US Army Corps of Engineers ${ }_{\circledast}$

Engineer Research and

Development Center

StormSim: Metamodeling of Coastal Storm Hazards for Probabilistic Applications

\title{
Rapid Tidal Reconstruction with UTide and the ADCIRC Tidal Database
}

Marissa J. Torres and Norberto C. Nadal-Caraballo

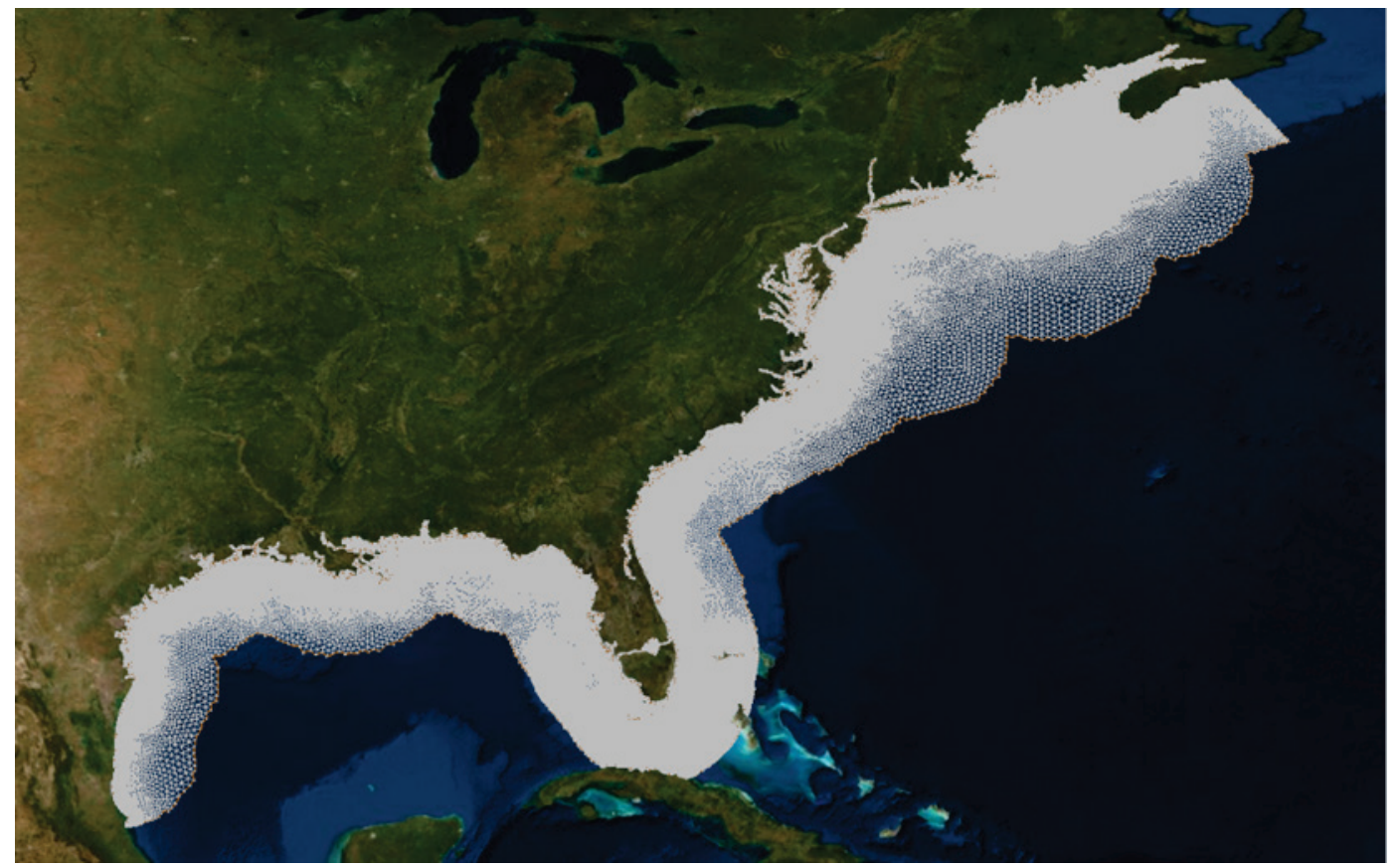


The US Army Engineer Research and Development Center (ERDC) solves the nation's toughest engineering and environmental challenges. ERDC develops innovative solutions in civil and military engineering, geospatial sciences, water resources, and environmental sciences for the Army, the Department of Defense, civilian agencies, and our nation's public good. Find out more at www.erdc.usace.army.mil.

To search for other technical reports published by ERDC, visit the ERDC online library at https://erdclibrary.on.worldcat.org/discovery. 


\title{
Rapid Tidal Reconstruction with UTide and the ADCIRC Tidal Database
}

\author{
Marissa J. Torres \\ Cold Regions Research and Engineering Laboratory \\ US Army Engineer Research and Development Center \\ 72 Lyme Road \\ Hanover, NH 03755-1290 \\ Norberto C. Nadal-Caraballo \\ Coastal and Hydraulics Laboratory \\ US Army Engineer Research and Development Center \\ 3909 Halls Ferry Road \\ Vicksburg, MS 39180-6199
}

Final report

Approved for public release; distribution is unlimited.

\footnotetext{
Prepared for US Army Engineer Research and Development Center Vicksburg, MS 39180

Under Funding Account Code U4368973; AMSCO Code 031398
} 


\section{Abstract}

The quantification of storm surge is vital for flood hazard assessment in communities affected by coastal storms. The astronomical tide is an integral component of the total still water level needed for accurate storm surge estimates. Coastal hazard analysis methods, such as the Coastal Hazards System and the StormSim Coastal Hazards Rapid Prediction System, require thousands of hydrodynamic and wave simulations that are computationally expensive. In some regions, the inclusion of astronomical tides is neglected in the hydrodynamics and tides are instead incorporated within the probabilistic framework. There is a need for a rapid, reliable, and accurate tide prediction methodology to provide spatially dense reconstructed or predicted tidal time series for historical, synthetic, and forecasted hurricane scenarios. A methodology is proposed to combine the tidal harmonic information from the spatially dense Advanced Circulation hydrodynamic model tidal database with a rapid tidal reconstruction and prediction program. In this study, the Unified Tidal Analysis program was paired with results from the tidal database. This methodology will produce reconstructed (i.e., historical) and predicted tidal heights for coastal locations along the United States eastern seaboard and beyond and will contribute to the determination of accurate still water levels in coastal hazard analysis methods.

DISCLAIMER: The contents of this report are not to be used for advertising, publication, or promotional purposes. Citation of trade names does not constitute an official endorsement or approval of the use of such commercial products. All product names and trademarks cited are the property of their respective owners. The findings of this report are not to be construed as an official Department of the Army position unless so designated by other authorized documents. 


\section{Contents}

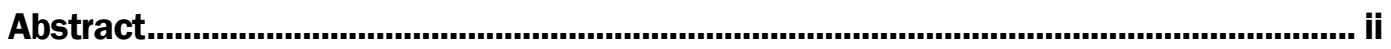

Figures and Tables ................................................................................................... iv

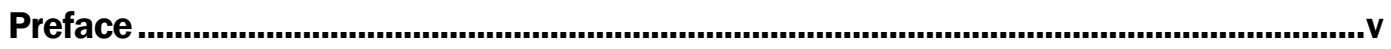

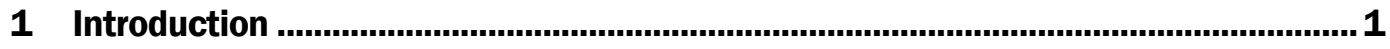

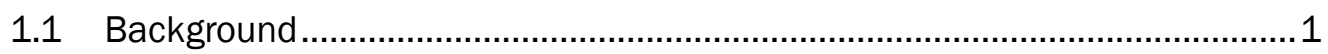

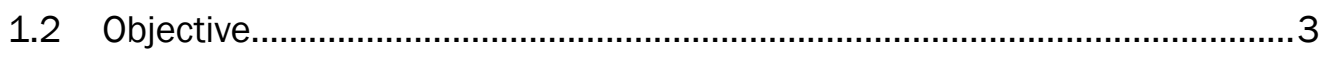

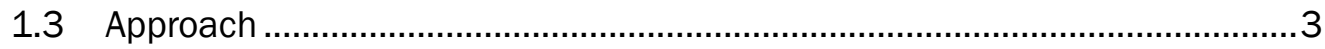

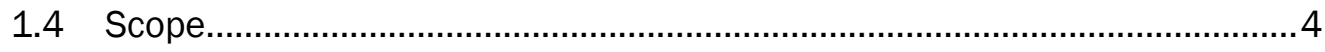

2 Astronomical Tides: Fundamentals, Modeling, and Analysis................................. 5

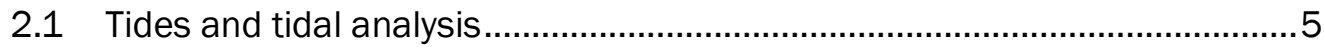

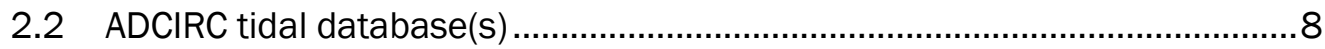

2.3 Unified tidal analysis program ........................................................ 12

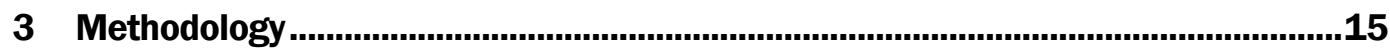

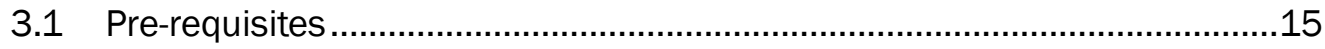

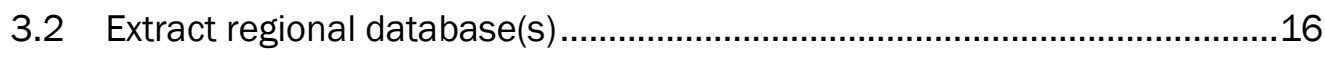

3.3 Extract regional harmonic elevation and velocity ...................................... 20

3.4 Reconstructing tidal time series............................................................. 23

3.4.1 Preparing UTide coefficient structure ........................................................... 24

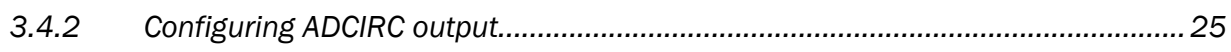

3.4.3 Running UTide ................................................................................... 26

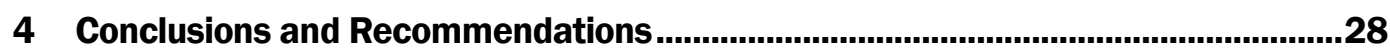

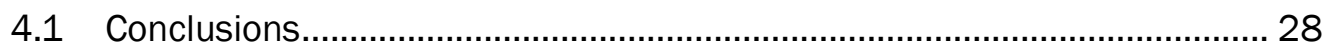

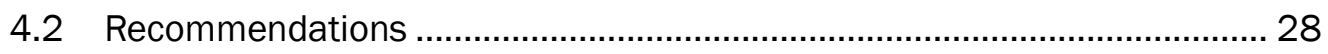

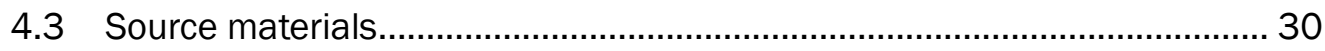

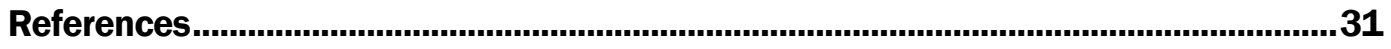

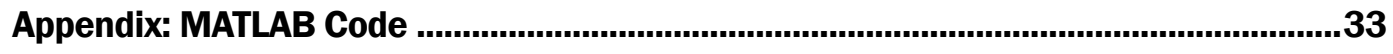

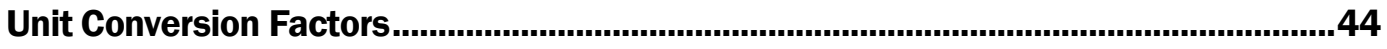

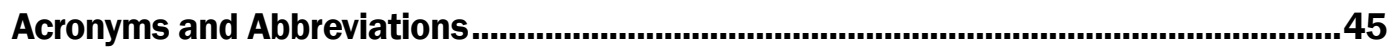

Report Documentation Page 


\section{Figures and Tables}

\section{Figures}

Figure 1. ADCIRC Western North Atlantic, Caribbean, and Gulf of Mexico (WNAT) (right) and ENPAC (left) tidal database meshes, versions ec_2015 with 2,066,216 nodes and wc_2015 with 272,913 nodes, respectively.

Figure 2. Example interactive prompt of the resultScope() program..................................18

Figure 3. Example interactive prompt of the $d b \_$extract() program...................................21

Figure 4. Example output file format of elev_hc.out (left) and vel_hc.out (right) from $d b \_$extract() program for three locations. 23

Figure 5. Example of expanded UTide structured array, coef, generated by ut_solv() for a group of records.

\section{Tables}

Table 1. Physical description of the eight most common tidal harmonic constituents

Table 2. ADCIRC tidal database boundary conditions. .10

Table 3. Input requirements to execute resultScope() program with sample input values.

Table 4. Description and example of the infile for the $d b$ extract() program.

Table 5. Input requirements to execute $d b \_$extract() program with sample input values. 


\section{Preface}

This study was conducted for the US Army Engineer Research and Development Center (ERDC) as part of the Coastal Hazards System and StormSim: Metamodeling of Coastal Storm Hazards for Probabilistic Applications, funded by the Flood and Coastal Systems Research and Development Program under Funding Account Code U4368973; AMSCO Code 031398. This work was undertaken in response to the following Flood and Coastal Risk Management Statements of Need: 2017-F-17 Stochastic Coastal Forcing Data Used for Coastal Structure Design, 2017-F-33 Uncertainty in Design Flood Estimates, 2017-F-34 Model Uncertainty, 2017-F-43 Future Conditions, and 2014-F-29 Frequency Estimates for Extreme Flood Events. Technical review of this study was provided by Ms. Mary A. Cialone and Mr. Gregory Slusarczyk, Coastal and Hydraulics Laboratory, Flood and Storm Protection Division, Coastal Processes Branch

The work was performed by the Engineering Resources Branch (ERB) of the Research and Engineering Division, US Army Engineer Research and Development Center (ERDC), Cold Regions Research and Engineering Laboratory (CRREL), and the Harbors, Entrances, and Structures Branch of the Navigation Division, ERDC Coastal and Hydraulics Laboratory (CHL). At the time of publication of this report, Dr. Caitlin Callaghan was Branch Chief (ERB); Mr. George Calfas was Acting Division Chief (Research and Engineering Division); and Dr. Robert Davis was the Technical Director for Geospatial Research and Engineering. The Deputy Director of ERDC-CRREL was Mr. David B. Ringelberg, and the Director was Dr. Joseph L. Corriveau. In ERDC-CHL, Mr. Chad Bounds was Branch Chief (Harbors, Entrances, and Structures Branch); Ms. Ashley Frey was Division Chief (Navigation Division); and Mr. Charles Edward Wiggins was the Technical Director for Navigation Research and Development. The Deputy Director of ERDC-CHL was Mr. Keith Flowers, and the Director was Dr. Ty V. Wamsley.

The Commander of ERDC was COL Teresa A. Schlosser, and the Director was Dr. David W. Pittman. 


\section{Introduction}

Through a combination of rainfall, storm surge, wind, and waves, coastal storms can have dramatic negative impacts to coastal communities and the national economy. Since 2005, the top five most destructive storms have resulted in a staggering combined $\$ 485.9$ billion (US dollars) in damages (https://www.ncdc.noaa.gov/billions). Storm surge is defined as the storminduced increase in the water surface elevation above the expected astronomical tide. Storm-induced water level increases are primarily a result of the winds and low atmospheric pressure associated with tropical cyclones (TCs) and extratropical cyclones (XCs) and are typically the most significant source of flooding in the coastal environment. The quantification of storm surge is an integral component of the flood hazard assessment of structures and facilities located in coastal areas.

\subsection{Background}

In the Atlantic basin, tropical cyclones are generally referred to as hurricanes. As a hurricane approaches the coastline, both the timing of landfall and the level of the astronomical tide at the landfall location are critical in determining the magnitude of the still water level (i.e., storm surge + wave setup + astronomical tide). Advancements in high-performance computing and numerical modeling have resulted in the development of high-fidelity storm surge and wave simulation models that produce an accurate and detailed representation of physical (hydrodynamic) processes that can support high-accuracy forecasting applications.

Coastal hazard analysis methods typically include a large suite of coupled hydrodynamic and wave model simulations that predict the storm response of several hundred to thousands of TC and XC scenarios. For example, the Advanced Circulation (ADCIRC) hydrodynamic model (Luettich et al. 1992; Westerink et al. 1993) and the Steady-State Spectral Wave model (Massey et al. 2011) are commonly coupled for such purposes. Storm responses, as well as the corresponding probabilistic coastal hazard analysis parameters (e.g., annual exceedance probability), are written to select numerical save points representing physical locations of interest within the study domain. This practice is true for large regional studies such as the North Atlantic Coast Comprehensive Study (NACCS) (NadalCaraballo et al. 2015) and the ongoing South Atlantic Coastal Study 
(SACS). Establishing this ensemble is computationally expensive and requires several thousand processing units to compute. For regions with minimal tidal range, on the order of $0.5 \mathrm{~m}^{1}$ or less, the hydrodynamic simulations are typically run without base tidal conditions included, and astronomical tides are instead incorporated within the probabilistic framework.

There is a need for a rapid, reliable, and accurate tide prediction methodology to provide spatially dense reconstructed or predicted tidal time series for historical, synthetic, and forecasted hurricane scenarios. Tidal prediction is accomplished by utilizing existing numerical frameworks that execute modern harmonic analysis techniques. Generally, for harmonic analysis, a record of tidal height observations (e.g., water elevation time series) is required to decompose the record into its subsequent harmonic amplitude and phase pairs. These pairs are then used to predict new records of tidal heights for various time periods. Though, observation gages may be sparse for some coastal communities. Alternatively, existing regional tidal databases provide harmonic amplitude and phase data over a high-resolution (i.e., spatially dense) numerical mesh. Existing coastal hazard analysis tools, such as the Coastal Hazards System (CHS) and the Stochastic Storm Simulation System (StormSim), developed and maintained by the US Army Engineer Research and Development Center, Coastal and Hydraulics Laboratory, would benefit greatly from an enhanced tidal prediction method.

The CHS (https://chs.erdc.dren.mil) is a national database and web tool that provides Probabilistic Coastal Hazard Analysis (PCHA) (Nadal-Caraballo et al. 2020) products developed from regional studies such as the NACCS (Nadal-Caraballo et al. 2015), and the ongoing SACS. The CHS contains comprehensive, high-fidelity, storm-response numerical modeling results including storm climatology, storm surge, water level, waves, and currents with corresponding epistemic uncertainties. CHS also stores extreme value statistics of observed waves and water level responses. Observations in CHS include water levels, waves, and meteorological parameters such as wind and atmospheric pressure. The data can be easily accessed, mined,

\footnotetext{
1 For a full list of the spelled-out forms of the units of measure used in this document, please refer to US Government Publishing Office Style Manual, 31st ed. (Washington, DC: US Government Publishing Office 2016), 248-52, https://www.govinfo.gov/content/pkg/GPO-STYLEMANUAL-2016/pdf/GPOSTYLEMANUAL-2016.pdf.
} 
plotted, and downloaded through a user-friendly web tool. PCHA considers hazards due to both tropical and extra-tropical cyclones, depending on the storm climatology of the region of interest. The CHS supports feasibility studies, probabilistic design of coastal structures, flood risk management for coastal communities and critical infrastructure.

The StormSim (https://stormsim.erdc.dren.mil) is a suite of tools that provide probabilistic modeling and statistical analysis of historical and synthetic TCs and XCs. Of these tools, the Coastal Hazards Rapid Prediction System (CHRPS) (Torres et al. 2020) performs rapid prediction of coastal storm hazards, including real-time, hurricane-induced flooding and risk assessment. The research conducted to develop the StormSim system resulted in standardized, robust, state-of-the-art extremal statistical methods and software tools that span a wide range of federal needs including coastal applications within research, emergency management, coastal planning, and coastal engineering. These applications include extremal marginal and joint statistical analysis of storm climatological parameters for TCs and XCs. In addition, the methods provide statistical tools for characterizing, analyzing, and simulating response parameters such as surge elevation, wave height, wave direction, wave period, wave power index, total water level, and storm duration in a statistical context. The development of StormSim is an ongoing effort that has been funded through US Army Corps of Engineers (USACE), Navigation Systems and Flood \& Coastal Storm Reduction Civil Works Research programs.

\subsection{Objective}

The objective of this work is to produce reconstructed (i.e., historical) and predicted (i.e., forecast) tidal heights for coastal locations along the US eastern seaboard and beyond. Historical and forecast records of astronomical tides will contribute to the determination of still water level in coastal hazard analysis methods, including StormSim.

\subsection{Approach}

The proposed methodology seeks to combine the harmonic elevation information defined in the ADCIRC tidal database with the harmonic analysis methods of the Unified Tide (UTide) tidal analysis program. First, tidal harmonic amplitude and phase pairs are extracted from a regional subset of the ADCIRC database. These pairs are then configured for implementation in the UTide tidal reconstruction program. Last, tidal 
heights are rapidly reconstructed or predicted over a user-specified time period and stored in a database, like the CHS, or implemented in real-time still water level (SWL) estimate, like in the CHRPS.

\subsection{Scope}

In this document, information about two ADCIRC tidal databases is presented and described. The proposed methodology discussed herein focuses solely on the Western North Atlantic database, though the methods are applicable to the Eastern North Pacific database as well. In addition, the UTide tidal analysis program is capable of processing not only tidal heights but also tidal currents. The methods discussed herein focus solely on tidal heights, and some modifications and other considerations not included here would need to be followed to process tidal currents. Last, the proposed methodology was developed using a Windows operating system and the MATLAB software. As such, the installation and execution instructions are written for Windows, and scripts are executed from MATLAB. Users on different operating systems without a MATLAB license are advised to review the source materials for modified installation instructions and alternative programming languages. 


\section{Astronomical Tides: Fundamentals, Modeling, and Analysis}

In this section, a brief overview of the fundamentals of tides, tidal analysis, and tidal prediction methods is presented. In addition, the details of both the ADCIRC tidal database and the UTide program are introduced and summarized. The descriptions are intentionally brief and broad in scope with the appropriate sources referenced for further reading.

\subsection{Tides and tidal analysis}

The astronomical tide is the periodic rise and fall of the sea surface as a result of the gravitational interactions between the sun, moon, and Earth. In this system, the orientation of the celestial bodies relative to Earth dictates the timing (i.e., phase) and strength (i.e., amplitude) of the tide. The moon is the stronger of the two forces due to its proximity to Earth. As such, inter-annual variations in the astronomical tide tend to follow more closely the lunar cycle than the solar cycle (e.g., daily, fortnightly, and monthly cycles).

In general, the astronomical tide is composed of individual lunar and solar tide-producing forces known as harmonic constituents. Each constituent has its own amplitude, phase, and frequency. The frequency determines the species of the constituent, referring to diurnal (once per day) or semidiurnal (twice per day). While diurnal and semi-diurnal are the primary species, there are many shorter-period (e.g., fourth and sixth diurnal) and longer-period (e.g., monthly, semi-annual, and annual) constituents that naturally occur.

The amplitude and phase of each constituent varies with latitude from the equator. For example, the tidal range (difference between high tide and low tide) in the Gulf of Mexico and Caribbean seas is typically low ( 0.3 to $1.0 \mathrm{~m}$ ), and the tide is diurnal in nature. Meanwhile, the tidal range off the coast of Maine can reach upwards of $4 \mathrm{~m}$ and is generally semi-diurnal. For additional details about the foundation of the astronomical tides, the National Ocean Service (NOS) under the National Oceanic and Atmospheric Administration (NOAA) provides a more thorough description of tides and water levels through its education service (https://oceanservice.noaa.gov/education/tutorial_tides/welcome.html). 
There are several dozen known harmonic constituents, though only a few dozen are significant for nearshore coastal applications. The NOS has identified a suite of 37 tidal constituents that are sufficient for tidal prediction (Schureman 1958). Generally, the most ubiquitous tidal constituents are the four diurnal (K1, O1, P1, and Q1) and the four semidiurnal (M2, S2, N2, and K2) constituents. These constituents are commonly used as tidal forcing for storm surge simulations. Descriptions of the physical tide-producing force that each constituent represents can be found in Table 1 for the eight common constituents and on the NOAA Tides \& Currents Glossary webpage (https://tidesandcurrents.noaa.gov/glossary.html) for the remaining constituents.

Table 1. Physical description of the eight most common tidal harmonic constituents.

\begin{tabular}{|l|l|}
\hline Harmonic Constituent & Representative Force \\
\hline M2 & Principal lunar semidiurnal \\
\hline S2 & Principal solar semidiurnal \\
\hline N2 & Larger lunar elliptic semidiurnal \\
\hline K2 & Lunisolar semidiurnal \\
\hline 01 & Lunar diurnal \\
\hline K1 & Lunar diurnal \\
\hline P1 & Solar diurnal \\
\hline Q1 & Larger lunar elliptic diurnal \\
\hline
\end{tabular}

Each constituent is functionally a cosine curve, or a sinusoid. On a fundamental level, tidal heights $h$ at any time $t$ can be predicted with relative accuracy for a given location from the superposition, or summation, of the sinusoidal harmonic constituent amplitudes $\left(A_{k}\right)$ and phase-lags $\left(g_{k}\right)$. Additional factors include the constituent astronomical arguments $\left(V_{\mathrm{k}}\right)$, nodal factors $\left(f_{\mathrm{k}}\right)$ and nodal angles $\left(u_{\mathrm{k}}\right)$. With these considerations, tidal time series can be expressed (Equation 1). The variables $V_{\mathrm{k}}, f_{\mathrm{k}}$, and $u_{\mathrm{k}}$ are derived through harmonic analysis of year-long sea level observations.

$$
h(t)=\sum_{k=1}^{n} f_{k}(t) a_{k} \cos \left[\omega_{k} \tau+V_{k}\left(t_{0}\right)+u_{k}(t)-g_{k}\right]
$$


Here, $t$ is the reference time ( $\left.t_{o}\right)$ plus the time $(\tau)$ elapsed since $t_{o}$ (i.e., $t=$ $\left.t_{o}+\tau\right) ; n$ is the number of constituents, where the subscript $k$ denotes an individual tidal constituent; and $\omega_{i}$ designates the angular speed $\left({ }^{\circ} \mathrm{hr}^{-1}\right)$, or frequency, of the tidal constituents. More detail about the fundamental mathematical processes of harmonic analysis can be found in Schureman (1958) and Godin (1972). Further, the culmination of these methodologies and theories into a manual for practical application and interpretation of tidal analysis and prediction is provided in Parker (2007).

The understanding of modern harmonic analysis methods stems from Godin (1972). These methods typically apply the least squares regression technique to solve for the amplitudes and phases of the constituents that make up the tidal signal. The development of the first harmonic analysis code was completed in FORTRAN by Foreman $(1977,1978)$, and later, Pawlowicz et al. (2002) established the T_Tide program in MATLAB. Since then, a series of improvements to the current methodology was undertaken, including the addition of the iteratively reweighted least squares solution (Leffler and Jay 2009), and the incorporation of the nodal and astronomical argument corrections and multiple inference calculations into the least squares matrix directly (Foreman 2009). These improvements have since been added to the foundational FORTRAN code of Foreman (1977) and incorporated into the most recent tidal analysis program, UTide (Codiga 2011).

Note that tidal predictions represent only the known astronomical arguments in a given location. Additional variations in water level from meteorological (e.g., storm surge) or atmospheric (e.g., pressure fluctuations) phenomena are not included.

Further, global and regional ocean tidal models are needed to provide estimates of harmonic amplitude and phase-lags where sea level observations are sparse. Coastal ocean tidal models are typically used for coastal inundation and navigation studies in nearshore regions. The hydrodynamics of coastal tides is difficult to predict due to a number of complex coastal processes and characteristics, such as irregular coastlines, bathymetry of the ocean floor, and the interaction of astronomical tides with nonlinearly generated overtides and compound tides in shallow regions. This tidal problem cannot be directly solved analytically and requires the use of numerical models to evaluate sea surface elevations and currents. 


\subsection{ADCIRC tidal database(s)}

The ADCIRC hydrodynamic model is a general circulation model capable of simulating astronomical tides and storm surge propagation from far offshore to nearshore environments. The model solves the general wavecontinuity equation in conjunction with the primitive momentum equations over large, complex computational domains while providing high resolution and computational efficiency in the nearshore (Luettich et al. 1992; Westerink et al. 1993). ADCIRC is a prevalent tool among academic, corporate, and government institutions. A detailed description for the general application and capabilities of ADCIRC is available at http://adcirc.org/.

ADCIRC performs these hydrodynamic simulations over a computational domain known as a mesh. A mesh is a numerical surface consisting of nodes and elements representative of a physical surface, such as the ocean floor. There are two general types of meshes, structured and unstructured. A structured mesh, also known as a regular grid, is a rectangular surface with an equal number of elements connected to each node, similar to the pattern of a chess board. An unstructured mesh is a tessellation of triangles or tetrahedra shapes in an irregular pattern where 3-5 elements are connected to each node. In an unstructured mesh, the spatial resolution is inhomogeneous, meaning the Euclidean distance between nodes varies over the domain. This capability is both popular and practical in the numerical modeling community. With an unstructured mesh, the spatial resolution over open-ocean regions is generally low (i.e., the distance between nodes is greater) whereas spatial coverage of nearshore regions of interest where greater hydrodynamic change occurs (e.g., coastal inlet) is much higher (i.e., distance between nodes is lower). This practice is most practical for computational efficiency when executing model simulations.

Over the past two decades, two coastal ocean tidal models have been developed and refined using ADCIRC. These databases were established to allow water surface elevation and current to be easily defined in both open-ocean and coastal environments. The tidal model domains include the Western North Atlantic (WNAT) and Eastern Pacific (ENPAC) basins. Both computational domains are inherently large to improve the overall accuracy of ocean circulation (Mukai et al. 2002). 
The WNAT model domain (Szpilka et al. 2016) encompasses the Western North Atlantic Ocean (Maine to Florida Keys), the Gulf of Mexico (Texas to Western Florida), and the Caribbean Sea (Puerto Rico and the US Virgin Islands) (Figure 1). The open ocean boundary extends to the $60^{\circ} \mathrm{W}$ meridian. The latest version of the WNAT model domain (circa 2015) contains 2,066,216 nodes and 3,770,720 elements, with a minimum (maximum) spatial resolution of $13 \mathrm{~m}(46 \mathrm{~km})$ in Puerto Rico and Long Island (open boundary) regions. The average spatial resolution, or element length, along the US coastline is $250-500 \mathrm{~m}$, with increased resolution in inland channels and inlets (Szpilka et al. 2016).

Figure 1. ADCIRC Western North Atlantic, Caribbean, and Gulf of Mexico (WNAT) (right) and ENPAC (left) tidal database meshes, versions ec_2015 with 2,066,216 nodes and wc_2015 with 272,913 nodes, respectively.

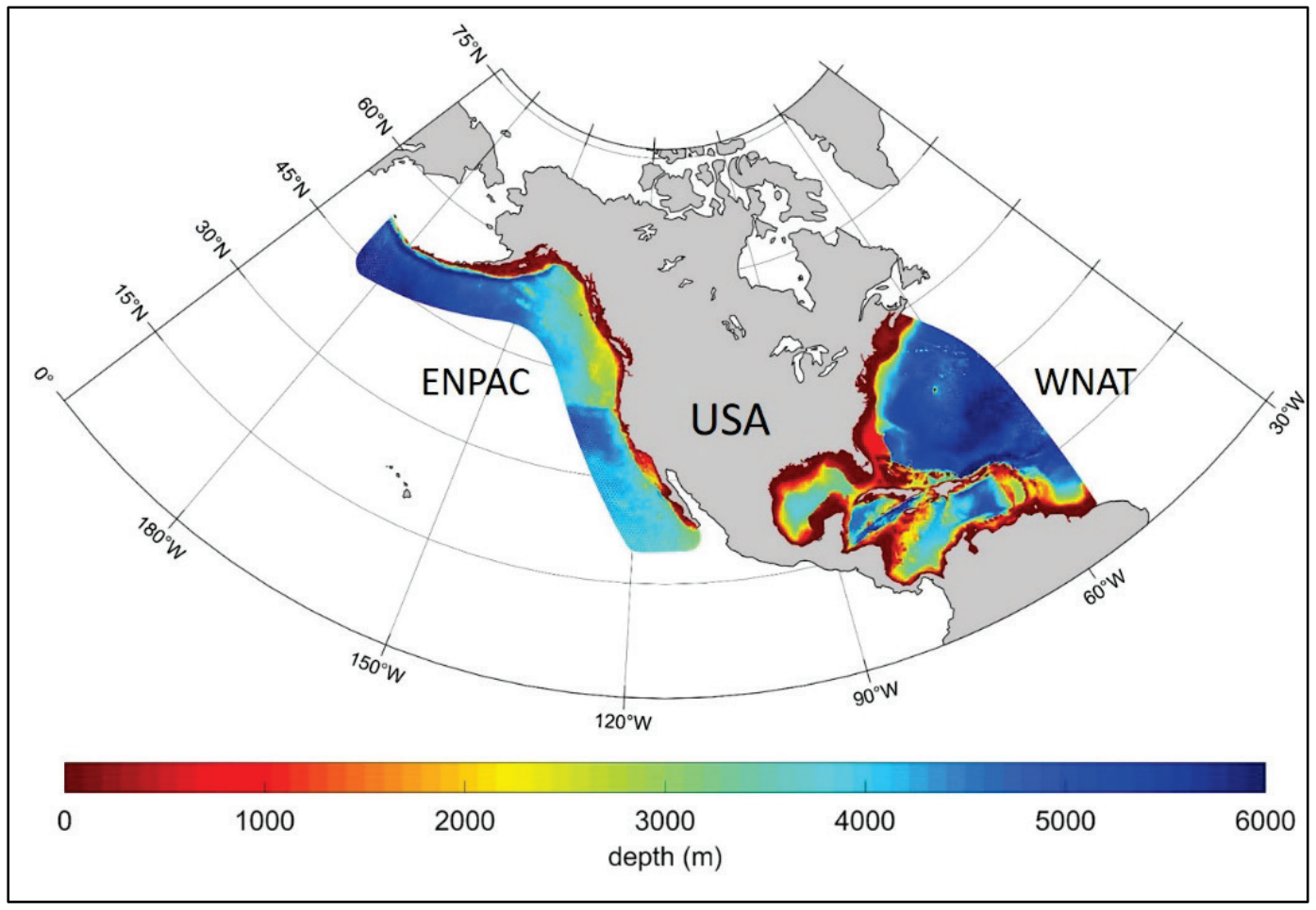

The ENPAC model domain (Szpilka et al. 2018) encompasses the Eastern North Pacific Ocean from southwestern Alaska (Bering Strait) along the US and Canadian coastlines, through southern California and the Baja Peninsula in Mexico (Figure 1). The domain boundary was designed to follow the coastline instead of including the entire geographic region, thereby reducing the overall computational burden while maintaining accurate circulation nearshore. This configuration does not include Hawaii or northern Alaska. The most recent version of the ENPAC model (circa 
2015) contains 553,802 nodes and $1,038,443$ elements, with a minimum (maximum) spatial resolution of $28 \mathrm{~m}(85 \mathrm{~km})$ in coastal (deep ocean) regions. The average coastal resolution is $200-400 \mathrm{~m}$, though the Alaskan coastline is not as resolved with element lengths between 2 and $5 \mathrm{~km}$ in that region (Szpilka et al. 2018). The downloadable materials and instructions for the coastal ocean tidal databases, as well as the supporting historical documentation, can be found at http://adcirc.org/products/adcirc-tidaldatabases/.

Each database was developed from an ADCIRC simulation of 410 days. The simulation time included a 25-day ramp period to adequately stabilize the water surface elevation over the domain. The model ran for an additional 20 days before the internal ADCIRC harmonic analysis routine was initiated at a 1 min interval for the remaining 365 days in the simulation. In addition to the eight primary constituents (M2, S2, N2, K2, O1, K1, P1, and Q1), each model was forced with the tidal amplitudes and potentials of the lunisolar fortnightly (Mf) and the lunar monthly (Mm) constituents. The WNAT database was additionally forced with shallowwater constituents (M4, MN4, and MS4) due to the effects of the Atlantic continental shelf on tidal propagation. Tidal forcing was extracted from the Oregon State University TOPEX/Poseidon Global Inverse Solution Tidal Model (TPXO) global tidal database. TOPEX/Poseidon was a joint satellite altimeter mission between the National Aeronautics and Space Administration (the US space agency) and the Centre National d'Etudes Spatiales (the French space agency) to map ocean surface topography. The details and differences between the WNAT and ENPAC simulations are described in Table 2. Further details about the WNAT and ENPAC model setup (e.g., bathymetry, bottom friction, boundary forcing) are discussed in their respective studies (Szpilka et al. 2016, 2018).

Table 2. ADCIRC tidal database boundary conditions.

\begin{tabular}{|l|l|l|l|}
\hline Database & $\begin{array}{l}\text { TPXO } \\
\text { Version }\end{array}$ & Boundary Conditions & Start Date \\
\hline $\begin{array}{l}\text { Western } \\
\begin{array}{l}\text { North } \\
\text { Atlantic }\end{array}\end{array}$ & 7.2 & $\begin{array}{l}\text { O1, K1, P1, Q1, M2, N2, S2, K2, Mf, } \\
\text { Mm, M4, MN4, MS4 }\end{array}$ & 17 November 1991 \\
\hline $\begin{array}{l}\text { Eastern } \\
\text { Pacific }\end{array}$ & 8.0 & $\begin{array}{l}\text { O1, K1, P1, Q1, M2, N2, S2, K2, Mf, } \\
\text { Mm }\end{array}$ & 16 November 2004 \\
\hline
\end{tabular}


In general, ADCIRC is commonly executed in its two-dimensional, depthintegrated form (ADCIRC-2DDI) for coastal hydrodynamic modeling applications. The model uses the depth-integrated mass and momentum conservation equations with the incompressibility, Boussinesq, and hydrostatic pressure approximations applied (Westerink et al. 1993). Astronomical tides are computed using the effective Newtonian equilibrium tide potential (Equation 2) (Westerink et al. 1993).

$$
\eta(\lambda, \varphi, t)=\sum_{n, j} \alpha_{j n} C_{j n} f_{j n}\left(t_{0}\right) L_{j}(\varphi) \cos \left[\frac{2 \pi\left(t-t_{0}\right)}{T_{j n}+j \lambda+v_{j n}\left(t_{0}\right)}\right]
$$

where

$$
\begin{aligned}
\eta= & \text { the effective Newtonian equilibrium tide potential } \\
\lambda, \varphi= & \text { degrees of longitude and latitude, respectively } \\
t= & \text { time } \\
t_{0}= & \text { a reference time } \\
j= & \text { the tidal species: } \\
& j=0 \text { : declinational } \\
& j=1 \text { : diurnal } \\
& j=2 \text { : semidiurnal } \\
\alpha_{j n}= & \text { the effective earth elasticity factor for tidal constituent } n \text { of } \\
& \text { species } j \\
C_{j n}= & \text { a constant characterizing the amplitude of tidal constituent } n \\
& \text { of } \operatorname{species} j \\
f_{j n}= & \text { the time-dependent nodal factor } \\
v_{j n}= & \text { the time-dependent astronomical argument } \\
T_{j n}= & \text { the } \operatorname{period}_{\text {of }} \text { constituent } n \text { of species } j \\
L_{j}= & \operatorname{changes~with~species~} j: \\
& L_{0}=3 \sin ^{2}(\varphi-1) \\
& L_{1}=\sin ^{2}(2 \varphi) \\
& L_{2}=\cos ^{-1}(\varphi) .
\end{aligned}
$$

Both the WNAT and ENPAC models were validated for the eight primary harmonic constituents (O1, K1, P1, Q1, M2, N2, S2, and K2). Statistical validation against the NOS Center for Operational Oceanographic Products and Services (CO-OPS) (https://tidesandcurrents.noaa.gov/about.html) and the International Hydrographic Organization (IHO) (https://iho.int/) tidal stations in open-ocean and coastal regions showed that the overall error of the WNAT database was minimal in both amplitude ( $0.7 \mathrm{~cm}$ on average) 
and phase (less than $20^{\circ}$ lag or lead on average) for the eight primary constituents (Szpilka et al. 2016). Similarly, the ENPAC data were validated against tidal stations from NOS CO-OPS and IHO, as well as the Institute of Ocean Sciences, Fisheries and Oceans Canada. The overall error of the ENPAC database was also minimal in amplitude $(1.1 \mathrm{~cm}$ on average) and phase (within $5^{\circ}-10^{\circ}$ ) for the same constituents (Szpilka et al. 2018).

The comprehensive guidance for use of these coastal ocean tidal databases as forcing for local or regional hydrodynamic models is expressed in the supporting literature (Szpilka et al. 2016, 2018). In general, caution is advised for applications where a larger suite of tidal constituents is of interest, as only 8 of the 37 constituents have been validated. Further, certain physical processes were not included in the model simulation, including density driven flows, riverine discharge, large-scale oceanic currents, or wind and pressure driven flows.

\subsection{Unified tidal analysis program}

UTide builds upon the frameworks established by Foreman et al. (2009), Leffler and Jay (2009), and Pawlowicz et al. (2002) and integrates these approaches into a single common framework. The tidal analysis program is designed to handle multi-year records of tidal heights, or tidal currents, which may be irregularly distributed (e.g., gap in observations). Multiple locations, or groups of records, can be processed in a single function call. The program also provides comprehensive diagnostics and confidence intervals of its harmonic analysis estimates relative to the observations (Codiga 2011). T_Tide (Pawlowicz et al. 2002) remains to be the most widely used harmonic analysis method for tidal prediction, though the advancements in predictive capability offered by UTide are preferred for longer records of tides (Byun and Hart 2019).

UTide is available in both the MATLAB and Python programming languages, though the Python version is still in development. There are two primary functions within the self-contained program: (1) a solver that decomposes an observed tidal time series into its harmonic components ut_solv() and (2) a predictor that reconstructs the time series over a userspecified period using the output from the solver - ut_reconstr().

UTide uses an iterative least squares fit approach (Leffler and Jay 2009) that includes the nodal, astronomical, and inference corrections (Foreman 
et al. 2009) to efficiently solve for the harmonic constituents in a given time series (Equation 3) (Foreman et al. 2009). The framework minimizes the influence of outliers in its final solution.

$$
h\left(t_{j}\right)=Z_{0}+a t_{j}+\sum_{k=1}^{n} f_{k}\left(t_{j}\right) A_{k} \cos \left[V_{k}\left(t_{j}\right)+u_{k}\left(t_{j}\right)-g_{k}\right]+R\left(t_{j}\right)
$$

where

$$
\begin{aligned}
h\left(t_{j}\right)= & \text { the water level measurement at time } t_{j} \\
Z_{0}= & \text { the constant background water level } \\
a= & \text { the linear trend coefficient for arbitrary sampling and multi- } \\
& \text { constituent inferences }
\end{aligned}
$$

$f_{k}\left(t_{j}\right), u_{k}\left(t_{j}\right)=$ nodal corrections for amplitude and phase, respectively, for constituent $k$ at time $t_{j}$

$A_{k}, g_{k}=$ the amplitude and phase lag of constituent $k$, respectively

$V_{k}\left(t_{j}\right)=$ the astronomical argument for constituent $k$ at time $t_{j}$ $R\left(t_{j}\right)=$ the nontidal residual.

UTide offers a flexible interface with various analysis configurations, including the ability to either specify or automatically infer harmonic constituents from a tidal record. The auto feature utilizes the Foreman $(1977,1978)$ automated design tree method to select the relevant constituents from the tidal height, or tidal current, observations. The supporting diagnostics describe the contribution of each constituent to the total energy of the record.

For groups of records, however, the auto feature is not available. Instead, an array of constituents must be specified manually. Users are advised to conduct preliminary harmonic analysis with a few representative locations in the group to determine an appropriate set of constituents (Codiga 2011). Each record in the group should be of the same length or have the same number of time stamps. Additional considerations and syntax for executing harmonic analysis on a group of records are described in Codiga (2011).

The output of the solver function, ut_solv(), is a structured array with multiple fields that stores the results of the harmonic analysis and summarizes the input configuration. Here, matrices of harmonic amplitude and phase of the specified constituents are listed for each member in the group, or conversely of the inferred constituents for a single record should the auto feature be invoked. This structure is the 
primary input for the reconstruction function, ut_reconstr(), in the program. From here, tidal heights can be reconstructed or predicted over a user-specified period of time.

Within the structured array, harmonic amplitude and phase from the ADCIRC tidal database can be inserted and used for tidal reconstruction. The methodology to do so is described in the following section. 


\section{Methodology}

The general requirements to install, compile, and use the ADCIRC WNAT tidal database are discussed in this section. In addition, the process of formatting ADCIRC database outputs for use as UTide inputs is described.

There are two programs available in the ADCIRC tidal database package (http://adcirc.org/products/adcirc-tidal-databases/). The first program resultScope() - allows users to define and extract a regional or local level database from the larger ADCIRC database, and the second program $d b \_$extract () - allows users to extract harmonic amplitudes and phases from the mesh or subgrid. Given the size of the database ( $>2$ million nodes), it is recommended to extract a smaller regional or local subgrid from which to pull harmonic constituent data. This sequence ultimately saves computational time and ensures a successful execution of $d b \_$extract. There are some supporting notes and documentation within the package available for review as well.

\subsection{Pre-requisites}

The methods presented herein were established using a Windows 10 Operating System (OS) and MATLAB 2018b. It is assumed that the reader is using a computer with a Windows OS and a current version of MATLAB installed to follow this procedure. If the reader is using a Linux or Mac OSX machine, the compilation instructions for the database will vary. If using UTide in Python instead of MATLAB, some of the functions discussed herein may not be available, and additional guidance should be sought from the developer documentation (https://pypi.org/project/UTide/).

First, download the WNAT tidal database package from the ADCIRC web page (http://adcirc.org/products/adcirc-tidal-databases/). The two programs of the ADCIRC tidal database are written in FORTRAN and will need to be compiled into executables. It is recommended to install a FORTRAN compatible Integrated Development Environment (IDE) that supports the GNU Compiler Collection. For example, the open-source, cross-platform software Code::Blocks (codeblocks.org) is an appropriate and relatively userfriendly IDE for this application. Installation instructions can be found on the corresponding developer web page. 
Once the IDE is installed, a supporting compiler will need to be downloaded and installed on the machine, such as the MinGW software (http://mingw-w64.org/doku.php). This process can be challenging for inexperienced or unfamiliar users. It is recommended that the user review related articles and tutorials to ensure correct installation and compatibility with the previously installed IDE.

Within the IDE, open the file HarmonicResultScope.f9o in the database package. Using the tools or options available in the IDE, compile the *.f9o FORTRAN script to build the resultScope.exe executable. If successful, the executable $\left({ }^{*}\right.$.exe) should appear in the working directory where the * foo file is located. If unsuccessful, review the errors within the IDE and research possible solutions. Follow the same procedure for the ADCIRC_db_extract_2012.foo file in the database package to compile the db_extract.exe executable.

The UTide MATLAB program can be downloaded from http://www.po.gso.uri.edu/ codiga/utide/utide.htm. Links to the Python version of UTide and the corresponding User's Manual (Codiga 2011) are available at this web page as well. There are three files included in the UTide package: (1) ut_solv.m, (2) ut_reconstr.m, and (3) ut_constants.mat. Save the files in the UTide folder within a relevant folder on the personal computer and add the UTide folder to the Path within the MATLAB environment. This step will allow the functions to be ubiquitous in MATLAB.

In addition to UTide, the ADCIRC Utilities MATLAB Toolbox (https://github.com/BrianOBlanton/adcirc util) is used to read, manipulate, and plot the ADCIRC WNAT mesh. Use of the utilities toolbox is optional, and its functionality depends on the intended application of the tidal database. For visualization purposes only, alternative programs compatible with the ADCIRC *.grd file (e.g., the Surface-water Modeling System) can be used. The utilities folder and subfolders are added to the MATLAB Path as well.

\subsection{Extract regional database(s)}

A regional or local database can be extracted from the greater ADCIRC WNAT or ENPAC databases with the resultScope() executable. Defining a regional database is encouraged to reduce the total searchable area, and thus the total computational time, when extracting harmonic elevation (amplitude and phase) and/or harmonic velocities. This step may only need to be completed once for each region of interest, as elevation and 
velocity harmonic information can be extracted from the regional or local database multiple times.

The program accepts three types of geometries that define the area of interest to be extracted: a circle, rectangle, or arbitrary shape. The user specifies which geometry type to use and the corresponding input specifications required for each case. The circle option requires the position of the circle center $(\mathrm{x}, \mathrm{y})$ in decimal degrees (longitude, latitude) and its diameter (meters). The rectangle option requires the coordinates of southwest and northeast corners of the rectangle, otherwise known as the diagonal. The specification of an arbitrary shape requires a separate coarse ADCIRC grid (*.grd) file. The extracted regional database will be the intersection of the specified geometry with the global ADCIRC database.

The resultScope() program can be executed in either an interactive or passive environment. The interactive environment is invoked by entering the *.exe itself. The user will be prompted to enter the necessary input values or filenames required to execute the program. A sample prompt and output sequence are displayed in Figure 2. The standard output from resultScope is the regional database grid file $\left({ }^{*}\right.$.grd), the regional harmonic elevation file $\left({ }^{*} .53\right)$, and the regional harmonic velocity file $\left({ }^{*} .54\right)$, as specified. The minimum requirements for the database extraction program are the regional grid and harmonic elevation files. Once the program finishes writing the regional harmonic or velocity files, the execution window will automatically close, and the output files ${ }^{*}$.grd, ${ }^{*} .53$, and ${ }^{*} .54$ ) will be available in the working directory from where the program was executed. The names of each file will be the project name entered as input to the program (e.g., CharlestonBay) (Figure 2). 
Figure 2. Example interactive prompt of the resultScope() program.

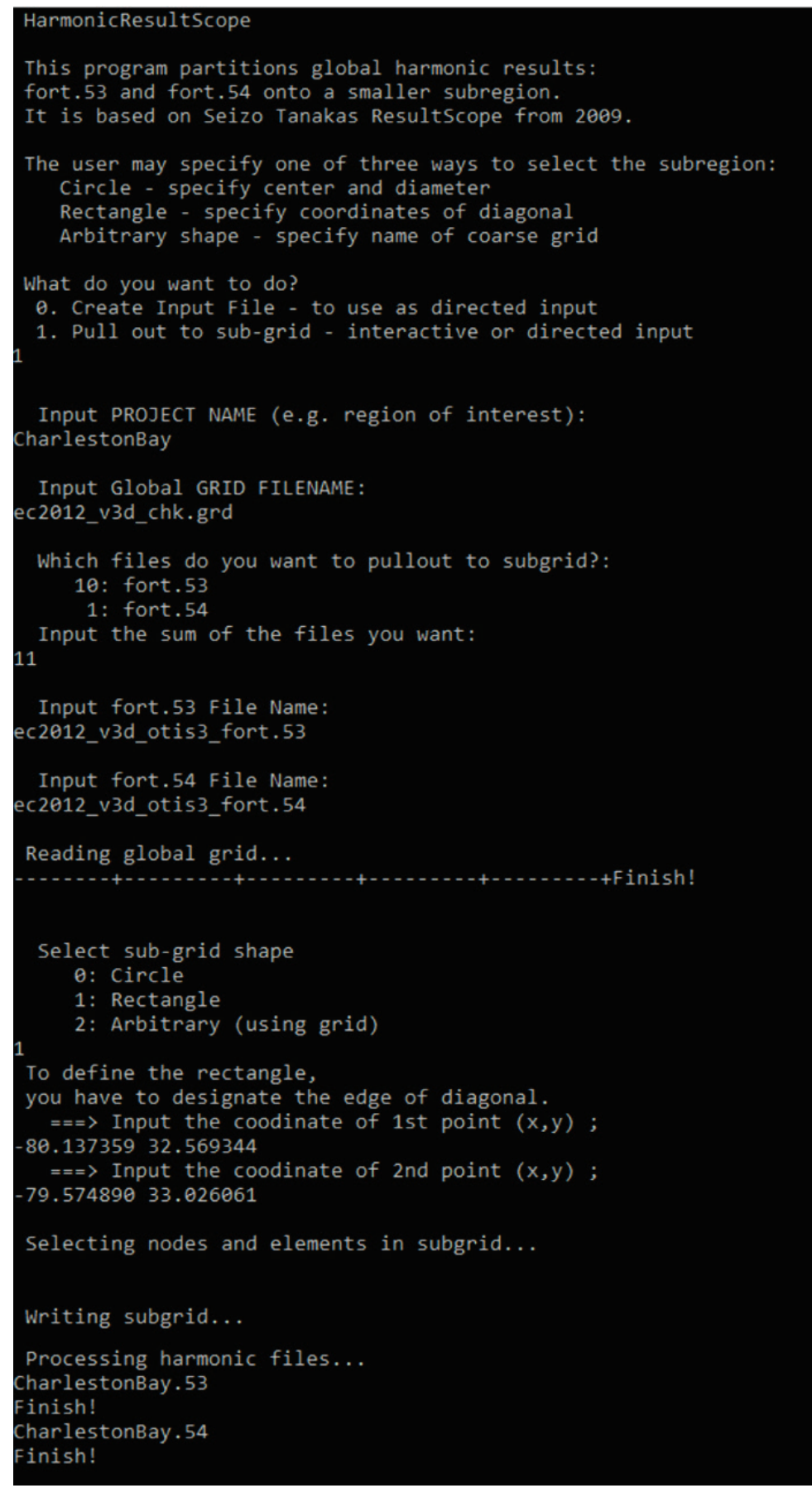

The interactive mode also offers the option to create an input file for the program to be executed in a passive environment. The input file for resultScope() contains the same input values and filenames that were requested from the interactive environment in a line-by-line sequence. A sample input file is presented in Table 3 with a description of the required inputs included. 
Table 3. Input requirements to execute resultScope() program with sample input values.

\begin{tabular}{|c|c|c|}
\hline Line \# & Input Description & Example Input \\
\hline 1 & Create input file (0) or extract sub-grid (1) & 1 \\
\hline 2 & Name of project & CharlestonBay \\
\hline 3 & $\begin{array}{l}\text { Relative path and filename of global database } \\
(* \text { grd })\end{array}$ & ./ec2012_v3d_chk.grd \\
\hline 4 & $\begin{array}{l}\text { Sum of harmonic file to extract: elevation (10), } \\
\text { velocity (1) }\end{array}$ & 11 \\
\hline 5 & $\begin{array}{l}\text { Relative path and filename of elevation } \\
\text { harmonic file }(* .53)\end{array}$ & ./ec2012_v3d_otis3_fort.53 \\
\hline 6 & $\begin{array}{l}\text { Relative path and filename of velocity } \\
\text { harmonic file }(* .54)\end{array}$ & ./ec2012_v3d_otis3_fort.54 \\
\hline 7 & Sub-grid shape: circle (0), rect. (1), arbitrary (2) & 1 \\
\hline \multirow{3}{*}{8} & (if circ.) Coordinates of center & -79.89530532 .768020 \\
\hline & (if rect.) Coordinates of SW corner & -80.13735932 .569344 \\
\hline & $\begin{array}{l}\text { (if arb.) Relative path and filename of coarse } \\
\text { grid file }\end{array}$ & ./charleston_regional.grd \\
\hline \multirow{2}{*}{9} & (if circ.) Diameter of circle in meters & 1500 \\
\hline & (if rect.) Coordinates of NE corner & -79.57489033 .026061 \\
\hline
\end{tabular}

The user can use the interactive mode to generate an input file, or the file can be created separately in a text editor or even with MATLAB. To execute resultScope() in the passive environment, the program should be executed within the command window, or MATLAB, with a pointer to the input file, as shown below. A sample script to generate input files and execute resultScope() within MATLAB is provided in the Appendix.

$$
\text { >> resultScope < charleston_grd.in }
$$

In either the interactive or passive environment, the computational time needed to extract a regional database from the global database is large, though the computational expense depends on the size of the regional domain of interest. Once the regional database has been defined, the harmonic elevation (amplitude and phase) and/or velocities can be extracted with the $d b \_$extract() program. 


\subsection{Extract regional harmonic elevation and velocity}

The elevation and velocity harmonics can be extracted at any location(s) within the regional database. The $d b \_$extract() program employs a KDTREE search algorithm to triangulate the three nearest nodes/elements in the regional database for each location specified by the user. The program requires three to four input files: (1) an infile containing a list of longitude/latitude (lon/lat) coordinates for extraction, (2) the regional database grid $\left({ }^{*}\right.$.grd), (3) the regional harmonic elevation file $\left({ }^{*} .53\right)$, and optionally, (4) the regional harmonic velocity file $\left({ }^{*} .54\right)$. Files $2-4$ are generated in the previous step with the resultScope() program while file 1 will need to be created specifically for the $d b \_$extract() program application.

The infile is a text file that first lists the total number of locations to be extracted, NOUT, followed by the lon/lat coordinates of each location on a separate line. A sample infile is provided in Table 4. If a coordinate is located outside the bounds of the regional database, the extraction program will return the harmonic elevation or velocity associated with the nearest node/element.

Table 4. Description and example of the infile for the db_extract() program.

\begin{tabular}{|l|l|l|}
\hline Line \# & Input Description & Example Input \\
\hline 1 & Total number of extraction points, NOUT & 4 \\
\hline 2 & Lon/lat coordinate of first extraction point & -66.69883442 .944540 \\
\hline 3 & Lon/lat coordinate of second extraction point & -66.84614542 .832420 \\
\hline$\ldots$ & & -66.79341542 .853550 \\
\hline NOUT & Lon/Lat coordinate of NOUT extraction point & -66.74318542 .874100 \\
\hline
\end{tabular}

The $d b \_$extract() program is executed in the same manner as the resultScope program. An interactive or passive environment is available for $d b \_$extract() as well. The interactive mode will prompt the user to enter the relative path and filename of the necessary input files. A sample prompt is displayed in Figure 3. 
Figure 3. Example interactive prompt of the db_extract() program.

ADCIRC_db_extract_2012 (pre-release)2013/04

-C. Szpilka

This program extracts harmonic constants

from any ADCIRC tidal database.

It uses the KDTREE2 algorithm to search for

the element for each extraction point.

What do you want to do?

(1) Extract elevation harmonics only

(2) Extract velocity harmonics only

(3) Extract both elevation and velocity

$==>3$

Enter file containing extraction points:

Note: first line lists number of points

followed by NOUT lines with their

locations

in east-positive long and lat

$==$ charleston_hc.in

Enter name of grid file used to create

tidal database:

$==$ CharlestonBay-sub.grd

Enter name of file containing

global elevation harmonics (fort.53):

$\Rightarrow$ CharlestonBay. 53

Enter name of file containing

global velocity harmonics (fort.54):

$==$ CharlestonBay. 54

Reading in extraction point locations ...Done!

Reading in database grid...Done!

Reading in elevation harmonics...Done!

Reading in velocity harmonics...Done!

Building KDTREE...done!

Creating translation table...done!

$* * * *$

RESULTS HAVE BEEN STORED IN OUTPUT FILES

elev_hc.out AND vel_hc.out AS APPROPRIATE

DIAGNOSTIC INFORMATION WRITTEN TO tides.dia FORTRAN STOP 
Otherwise, the user may generate an input file (Table 5) containing the same information as was prompted by the interactive mode. This input file can be generated either manually or automatically with MATLAB. The db_extract() program can be executed within the command window or MATLAB in a similar manner as resultScope(), as shown below.

$$
>>\text { db_extract }<\text { charleston_hc.in }
$$

Table 5. Input requirements to execute $d b \_$extract() program with sample input values.

\begin{tabular}{|l|l|l|}
\hline Line \# & Input Description & Example Input \\
\hline 1 & $\begin{array}{l}\text { Relative path and filename of extraction } \\
\text { points input file }\end{array}$ &.$/$ charleston_points.in \\
\hline 2 & $\begin{array}{l}\text { Relative path and filename of regional } \\
\text { database grid }\end{array}$ &.$/$ CharlestonBay-sub.grd \\
\hline 3 & $\begin{array}{l}\text { Relative path and filename of elevation } \\
\text { harmonic file }\end{array}$ &.$/$ CharlestonBay.53 \\
\hline 4 & $\begin{array}{l}\text { Relative path and filename of velocity } \\
\text { harmonic file }\end{array}$ &.$/$ CharlestonBay.54 \\
\hline
\end{tabular}

Three output files are generated by the $d b \_$extract() program. These include (1) the elevation amplitude and phase, elev_hc.out; (2) the velocity amplitude and phase, vel_hc.out; and (3) a diagnostic output detailing the results of the KDTREE search algorithm for each point, tides.dia. The output files (*.out) list the elevation or velocity amplitude and phase for the 37 fundamental tidal constituents used by NOAA at each point listed in the infile. A text heading is printed for each constituent followed by the list of NOUT amplitude and phase values (of type float) in the order listed in the infile. Figure 4 displays a sample of the expected output file format for both elev_hc.out and vel_hc.out. 
Figure 4. Example output file format of elev_hc.out (left) and vel_hc.out (right) from db_extract() program for three locations.

\begin{tabular}{|c|c|c|c|c|c|c|}
\hline \multicolumn{2}{|c|}{ elev_hc.out } & \multicolumn{5}{|c|}{ vel_hc.out } \\
\hline $\mathrm{M}(2)$ & & $M(2)$ & & & & \\
\hline 0.408926 & 46.252873 & & 0.002486 & 273.256 & 0.163088 & 323.637 \\
\hline 0.860560 & 93.962847 & & 0.006718 & 180.848 & 0.030857 & 354.741 \\
\hline 0.950486 & 97.931115 & & 0.019856 & 187.574 & 0.035416 & 7.739 \\
\hline $\mathrm{N}(2)$ & & $\mathbf{N}(2)$ & & & & \\
\hline 0.089296 & 24.176766 & & 0.000377 & 198.871 & 0.034380 & 302.879 \\
\hline 0.162916 & 75.183887 & & 0.000773 & 165.420 & 0.004959 & 334.556 \\
\hline 0.179185 & 79.631338 & & 0.003695 & 169.364 & 0.006585 & 349.535 \\
\hline$S(2)$ & & $s(2)$ & & & & \\
\hline 0.072075 & 60.785283 & & 0.000423 & 213.846 & 0.030169 & 340.005 \\
\hline 0.132234 & 121.788788 & & 0.000604 & 217.446 & 0.004214 & 22.003 \\
\hline 0.147382 & 126.933729 & & 0.003209 & 216.507 & 0.005719 & 36.707 \\
\hline$\circ(1)$ & & $O(1)$ & & & & \\
\hline 0.051403 & 197.338508 & & 0.000270 & 269.352 & 0.010245 & 104.135 \\
\hline 0.061896 & 208.855725 & & 0.000424 & 335.013 & 0.001413 & 121.355 \\
\hline 0.063658 & 210.066497 & & 0.000588 & 293.832 & 0.001061 & 114.056 \\
\hline $\mathrm{K}(1)$ & & $\mathrm{K}(1)$ & & & & \\
\hline 0.083319 & 176.824976 & & 0.000320 & 279.587 & 0.017353 & 89.393 \\
\hline 0.102572 & 190.656172 & & 0.000433 & 322.200 & 0.001760 & 104.203 \\
\hline 0.106072 & 192.356360 & & 0.001120 & 279.924 & 0.002003 & 100.134 \\
\hline $\mathrm{R}(2)$ & & $R(2)$ & & & & \\
\hline 0.022001 & 54.943180 & & 0.000134 & 233.303 & 0.009275 & 333.405 \\
\hline 0.040823 & 110.895097 & & 0.000219 & 193.590 & 0.001355 & 8.828 \\
\hline 0.045271 & 115.863868 & & 0.000993 & 205.146 & 0.001770 & 25.340 \\
\hline$L(2)$ & & L (2) & & & & \\
\hline 0.009403 & 132.418419 & & 0.000545 & 348.372 & 0.003601 & 29.401 \\
\hline 0.040377 & 122.303984 & & 0.000886 & 211.775 & 0.002359 & 30.887 \\
\hline 0.045204 & 123.400084 & & 0.000936 & 211.995 & 0.001679 & 32.219 \\
\hline $2 \mathrm{~N}(2)$ & & $2 \mathrm{~N}(2$ & & & & \\
\hline 0.003476 & 218.880496 & & 0.000154 & 50.043 & 0.001103 & 130.874 \\
\hline 0.008991 & 191.034441 & & 0.000248 & 268.580 & 0.000599 & 96.279 \\
\hline 0.009874 & 190.712327 & & 0.000181 & 281.224 & 0.000326 & 101.276 \\
\hline
\end{tabular}

A sample script to generate an infile and execute $d b \_$extract() within MATLAB is provided in the appendix. This script also moves the output files to a user-specified folder. This practice keeps the working directory free of clutter and promotes organization of input and output files.

\subsection{Reconstructing tidal time series}

This section details the process of generating a tidal elevation time series in UTide using the elevation amplitude and phase values from elev_hc.out. The generation of tidal currents from the velocity amplitude and phase output, vel_hc.out, is not considered in this document. In this example, tides are generated with the eight common harmonic constituents - M2, $\mathrm{S} 2, \mathrm{~N} 2, \mathrm{~K} 2, \mathrm{~K} 1, \mathrm{O} 1, \mathrm{Q} 1$, and P1. There are three essential steps to accomplish this task. The first step is generating the input matrix for the UTide reconstruction program, ut_reconstr(). This task requires the use of the UTide solver function, ut_solv(), on a sample NOAA tidal time series. Second, the elevation amplitude and phase values are converted into a format compatible with the UTide input matrix. Third, the user can reconstruct or predict tidal elevation time series for a specified latitude at 
a specified time using ut_reconstr(). The following paragraphs provide details on these three tasks for generating a tidal time series.

\subsubsection{Preparing UTide coefficient structure}

There are two components needed to execute the tidal reconstruction function, ut_reconstr(). The first is a specified time series along which to reconstruct or predict the tidal time series. The second, and most important, is the coefficient structure that specifies the names and frequencies of the constituents to use in the process, their corresponding amplitude and phase pairs, and the location(s) (i.e., latitudes) where tides are to be generated. This structure is generated from the solver function, ut_solv(), when decomposing a tidal time series into its harmonic components.

There are a number of options available in UTide when decomposing a tidal time series. A few of these were covered in Section 2.3, and more details can be found in both Codiga (2011) and in the comments of the ut_solv() function itself. It is the user's choice to determine how the harmonics are decomposed. Though, a few guidelines and recommendations for first-time users are provided here.

Consider a region of interest and select one or multiple NOAA tidal gauges in the area. Visit the NOAA Tides \& Currents webpage for a map-based selection product (https://tidesandcurrents.noaa.gov/map/index.html). Select either the NOAA predictions or the NOAA-verified time series product for a period of at least 28-29 days, covering at least one full lunar cycle. Use metric units and set the datum to mean sea level (MSL). A sampling interval of $1 \mathrm{hr}$ or $6 \mathrm{~min}$ is preferred. Download the time series as a Comma Separated Value file. Read the tidal time series into MATLAB and assign the data to a matrix where the rows correspond to time and the columns are the water level in meters. Use the datenum function to define time. Take note of the latitude of the tidal gauge location (decimal degrees). UTide will need this information to determine the phase of the tides.

UTide can process multiple stations in a single execution, so multiple columns of water level data can be included in the tidal time series matrix. The minimum requirements to execute $u t \_s o l v()$ are a time vector in datenum format covering the period of the tidal record, the matrix of tidal time series, the latitude of the selected station(s), and a character array of harmonic constituents to consider in the analysis. If processing multiple 
stations, this array of constituents is required. If processing a single station, the auto feature of UTide can be executed. With these components, execute ut_solv(). The output of this function is the coefficient structure, coef. An example of the expanded fields in the structure is shown in Figure 5. The options provided in ut_solv() will inform the coef structure and further dictate how tidal time series will be reconstructed in ut_reconstr(). An example MATLAB script that performs the above procedure is detailed in the appendix.

Figure 5. Example of expanded UTide structured array, coef, generated by ut_solv() for a group of records.

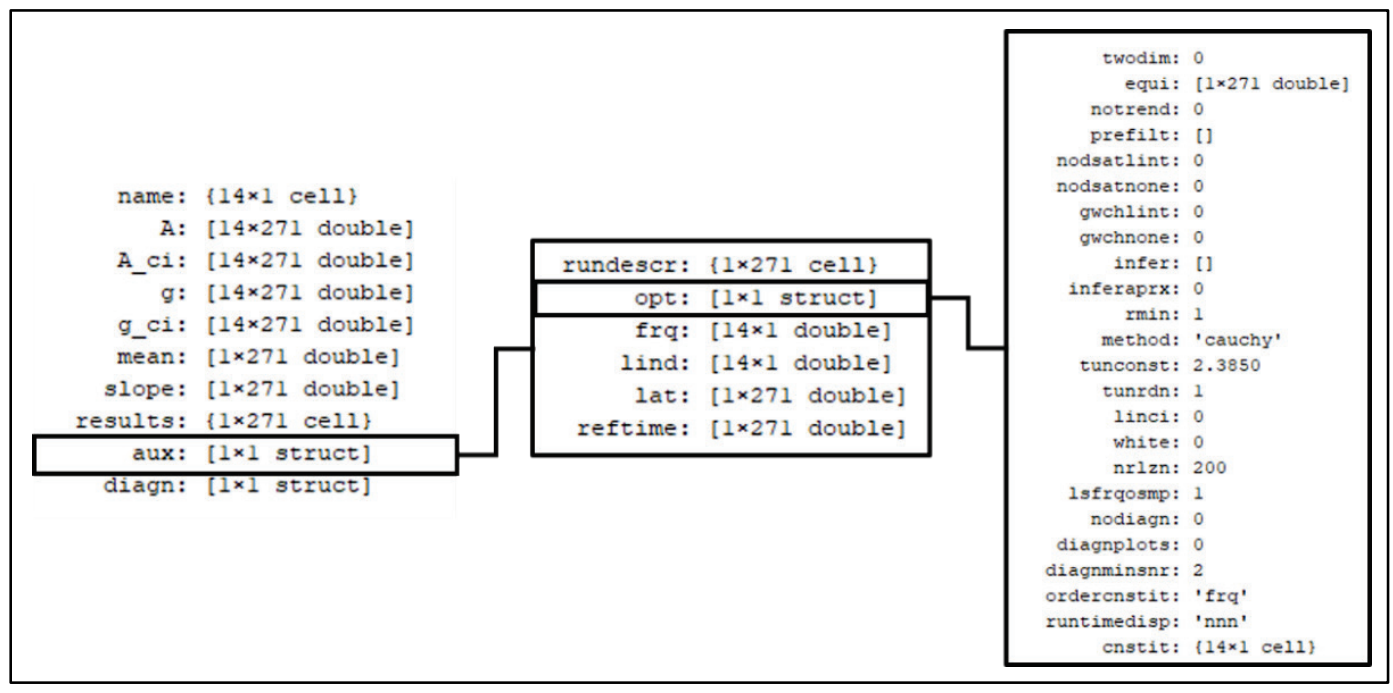

If interested in tidal currents, a similar procedure is followed. Tidal velocity in the $x$ and $y$ directions, or easting and northing, can be downloaded from select NOAA current gauges around the coast. Instead of submitting a matrix containing water levels, two matrices are required by ut_solv(), containing the easting velocity $(\mathrm{m} / \mathrm{s})$ and northing velocity $(\mathrm{m} / \mathrm{s})$, respectively. The latitude(s) of the selected stations and list of constituent names are required.

Note that not all fields in coef are required for implementation in ut_reconstr(). Descriptor fields, such as coef.results and coef.diagn, are not pertinent to the reconstruction process.

\subsubsection{Configuring ADCIRC output}

The $d b \_$extract() output file, elev_hc, is formatted such that the constituent name is printed and followed by the list of amplitude and phase pairs for each extraction point, which is then repeated for each of 
the 37 constituents. The structured array, coef, of UTide for an elevation time series run is formatted such that the amplitude $(A)$ and phase $(g)$ are separate fields. Both structures are of type double with dimensions $n \times m$, where $n$ is the number of constituents and $m$ is the number of stations.

The regional elev_hc file is first read into MATLAB. For each constituent listed, the corresponding amplitude and phase pairs are parsed into separate arrays. The constituents of interest, as specified in coef, are reshaped from a matrix of size $(1 \times m)$ to size $(m \times 1)$, satisfying the coef format. The resulting amplitude and phase pairs from the regional ADCIRC database are saved into an output structure similar to coef. The computational time required for this process is minimal for small areas, though it is subject to increase with an increase in the number of extraction locations specified in the $d b \_$extract() program.

The velocity harmonic information in vel_hc is formatted similar to elev_hc but includes the amplitude and phase pairs of the easting and northing velocity components for each constituent. While the conversion to a MATLAB matrix is the same, the coefficient structure for tidal currents in UTide is significantly more complex. The coefficient structure includes the following tidal current ellipse parameters: major axis, minor axis, current ellipse orientation angle, and phase lag between the two rotating components. Computation of the cosine and sine coefficients from the real-valued amplitude and phase of the easting and northing velocity components is outside the scope of this document.

\subsubsection{Running UTide}

At this step, the parsed amplitude and phase pairs from the ADCIRC regional database can be added to the UTide coefficient structure. The output structure from the previous step contains the amplitude and phase pairs in the appropriate format $(n \times m)$ and constituent order (sorted by naming order in coef.name). The amplitude matrix in coef can be directly replaced by the ADCIRC matrix, and the same is true for the phase matrix. Ideally at this stage, the same number of stations or locations are listed in coef as was extracted with $d b \_$extract(). This would imply that the number of locations, $m$, and their corresponding latitude locations, coef.aux.lat, are accurate in the structure.

The reconstruction function, ut_reconstr(), can generate tidal time series from the information in the coefficient structure for generally any 
specified time period. To execute the function, the reference time along which to generate the tides will need to be updated. Create a time vector in datenum format. Assign the median date of that vector to the reftime field in the coefficient structure, coef.aux.reftime. The reftime field should be a $(1 \times m)$ vector containing the median date repeated for as many stations or locations are included in the coefficient structure. Once this field is populated, ut_reconstr() can be executed along the specified time vector. The output is a matrix of reconstructed or predicted tidal time series where rows correspond to time and the columns are water levels (m, MSL) at each station or location. 


\section{Conclusions and Recommendations}

In the following sections, the objective and product of this work are reviewed and discussed. Recommendations for future considerations and implementation strategies are also presented.

\subsection{Conclusions}

The objective of this study was to combine the tidal harmonic information from the spatially dense ADCIRC tidal database with a rapid, reliable, and accurate tidal reconstruction and prediction program. UTide was selected as the tidal analysis tool for its robust handling of long-period and irregular tidal height records and its efficient management of tidal harmonic constituents. Installation instructions were provided for the required software and programs on the Windows OS. Example execution of scripts and input files were provided for the MATLAB programming language (see Appendix). The proposed methodology can supply historical and predicted tidal heights for still water level estimation in storm surge and coastal flooding analyses across the nation.

The product of this study is a master script that combines each of the processing steps discussed in this document into a single MATLAB file (see Appendix). The script details the necessary path, file, and variable specifications required by the user before the supporting functions are executed. Each function is included within the master script, allowing it to be self-contained. The prerequisite installation of MATLAB, the ADCIRC tidal database, and UTide (Section 3.1) is needed prior to running the master script. For repeated application of UTide predictions, the resulting coefficient structure (coef) from ut_solv() can be saved as a MATLAB *.mat file for later use within the ut_reconstr() function.

\subsection{Recommendations}

The rapid tidal predictive capability of UTide forced with ADCIRC constituents is ready for implementation in the CHS and StormSimCHRPS frameworks for both historical and real-time coastal hazard scenarios. The coastal hazard tools will leverage multiple UTide coefficient structures representative of tidal properties for specified regions of interest, such as the North or South Atlantic coasts. Regional harmonic analysis studies can be conducted to determine the appropriate tidal 
constituents needed to most accurately represent the tidal heights in the area. Efforts towards this goal have been completed in the Gulf of Mexico (Texas and Louisiana) and Caribbean Sea (Torres and Nadal-Caraballo 2020, 2021). Additional studies are ongoing for the North and South Atlantic at the time of this publication. Once the coefficient structure is adequately solved, the UTide reconstruction function $u t \_r e c o n s t r()$ can be executed over a given reference time as needed using a $\mathrm{C} \#$ wrapper around the MATLAB script within the system framework.

The overall computational time needed to generate tidal heights in UTide increases with an increase in the number of stations supplied and the length of the predicted time series. Therefore, for a large subset of stations, such as the dense spatial coverage of tidal nodes in a regional ADCIRC database, and/or for a long time record, it is recommended to precompute tidal heights across all nodes and store the results in a MATLAB *.mat file(s). The time series results are formatted such that each column represents a station, and each row is a time stamp of tidal height. Multiple *.mat files may need to be generated to fully represent the reference period due to size and memory limits.

This practice may be most helpful in preparation for real-time surge and hazard estimates for the current hurricane season in StormSim-CHRPS. In the CHRPS web tool, users will be able to monitor active TCs and predict storm surge in response to specific USACE requests for information. Precomputed tidal heights can be more readily accessed and displayed in the system with minimal delay, as opposed to predicting tidal heights at multiple locations within the system during user selection. Stored tidal node or station locations can be referenced by their corresponding coordinates (longitude, latitude).

In the context of historical storm scenarios, tidal heights will not be precomputed for each storm record and will instead be reconstructed in real time during user selection in the web tool. While this process may delay immediate visualization of tides in the web tool, the hindcast and storage of hundreds of historical storms are impractical. To balance the computational and storage requirements in the system, tidal heights that are reconstructed in response to user selection may be stored for later reference by other users interested in the same historical storm, especially if commonly referenced (e.g., Hurricane Katrina). 
The CHS in particular contains a large number of hydrodynamic and wave simulations for historical and synthetic tropical cyclone scenarios. For synthetic storm applications, tidal heights can be precomputed over a longer record (e.g., 5 to $10 \mathrm{yr}$ ) from which SWL estimates can be randomly sampled and implemented in the PCHA. This practice would require significant storage requirements depending on the length of the record and number of tidal nodes or stations included.

The overall computational expense of computing tides in MATLAB using a $\mathrm{C} \#$ wrapper in the system may be reduced by implementing the methods discussed in the Python programming language. The developer of UTide and UTide community members are actively preparing a version of the harmonic analysis tool in Python. Further development and testing are needed to bring the same functionality discussed here to the open source platform.

\subsection{Source materials}

Provided here is the list of sources where the resources discussed herein can be accessed.

Unified Tidal Analysis (UTide): http://www.po.gso.uri.edu/ codiga/utide/utide.htm

UTide Python: https://pypi.org/project/UTide/

Advanced Circulation (ADCIRC) hydrodynamic model: https://adcirc.org/

ADCIRC Tidal Databases: $\underline{\text { http://adcirc.org/products/adcirc-tidal-databases/ }}$

MATLAB: https://www.mathworks.com

Coastal Hazards Rapid Prediction System (CHRPS): https://stormsimchrps.erdc.dren.mil/

Coastal Hazards System (CHS): https://chs.erdc.dren.mil/ 


\section{References}

Byun, D.-S., and Hart, D. E. 2019. “On Robust Multi-Year Tidal Prediction Using T_TIDE.” Ocean Science Journal 54(4): 657-671. DOI: 10.1007/s12601-019o036-4.

Codiga, D. L. 2011. Unified Tidal Analysis and Prediction Using the UTide Matlab Functions. Technical Report 2011-01. Graduate School of Oceanography, University of Rhode Island, Narragansett, RI. ftp://www.po.gso.uri.edu/ pub/downloads/codiga/pubs/2011Codiga-UTide-Report.pdf

Foreman, M. G. G. 1977. Manual for Tidal Heights Analysis and Prediction. Pacific Marine Science Rep. 77-10. Institute of Ocean Sciences, Patricia Bay. Revised 2004. https://www.researchgate.net/publication/240106566_Manual_for_Tidal_Heights_Analysis_a nd_Prediction

Foreman, M. G. G. 1978. Manual for Tidal Currents Analysis and Prediction. Pacific Marine Science Rep. 78-6. Institute of Ocean Sciences, Patricia Bay. Revised 2004. https://www.researchgate.net/publication/264782849_Manual_for_Tidal_Currents_Analysis_a nd_Prediction

Foreman, M. G. G., J. Y. Cherniawsky, and V. A. Ballantyne. 2009. "Versatile Harmonic Tidal Analysis: Improvements and Applications.” J. Atmos. Oceanic Tech. 26: 806-817. DOI: 810.1175/2008JTECHO1615.1171

Godin, G. 1972. The Analysis of Tides. Toronto: University of Toronto Press.

Leffler, K. E., and D. A. Jay. 2009. "Enhancing Tidal Harmonic Analysis: Robust (hybrid L-1/L-2) Solutions.” Cont. Shelf Res. 29: 78-88.

DOI: 10.1016/j.csr.2008.1004.1011

Luettich, R. A., J. J. Westerink, and N. W. Scheffner. 1992. ADCIRC: An Advanced ThreeDimensional Circulation Model for Shelves, Coasts, and Estuaries, Report 1: Theory and methodology of ADCIRC-2DDI and ADCIRC-3DL. Tech Report DRP-92-6. Vicksburg, MS: US Army Engineer Waterways Experiment Station.

Massey, T. C., M. Anderson, J. M. Smith, J. Gomez, and R. Jones. 2011. STWAVE: Steady-State Spectral Wave Model User's Manual for STWAVE, Version 6.o. https://www.researchgate.net/publication/277787866_STWAVE_SteadyState_Spectral_Wave_Model_User's_Manual_for_STWAVE_Version_60

Mukai, A. Y., J. J. Westerink, and R. A. Luettich. 2002. Guidelines for Using Eastcoast 2001 Database of Tidal Constituents within Western North Atlantic Ocean, Gulf of Mexico, and Caribbean Sea. ERDC/CHL CHETN-IV-40. Vicksburg, MS: US Army Engineer Research and Development Center.

Nadal-Caraballo, N. C., J. A. Melby, V. M. Gonzalez, and A. T. Cox. 2015. North Atlantic Coast Comprehensive Study - Coastal Storm Hazards from Virginia to Maine. ERDC/CHL TR-15-5. Vicksburg, MS: US Army Engineer Research and Development Center. 
Nadal-Caraballo, N. C., V. Gonzalez, M.O. Campbell, M. J. Torres, J. A. Melby, and A. A. Taflanidis. 2020. "Coastal Hazards System: A Probabilistic Coastal Hazard Analysis Framework.” Edited by G. Malvárez and F. Navas. Global Coastal Issues of 2020. Journal of Coastal Research Special Issue No. 95: 1211-1216.

Parker, B. B. 2007. Tidal Analysis and Prediction. National Oceanic and Atmospheric Administration Special Publication NOS CO-OPS 3. Silver Spring, MD.

Pawlowicz, R., B. Beardsley, and S. Lentz. 2002. "Classical Tidal Harmonics Analysis Including Error Estimates in MATLAB Using T_TIDE.” Computers \& Geosciences 28: 929-937.

Schureman, P. 1958. Manual of Harmonic Analysis and Prediction of Tides; Special Publication 98. Washington, DC: Coast and Geodetic Survey, US Department of Commerce.

Szpilka, C., K. Dresback, R. Kolar, J. Feyen and J. Wang. 2016. "Improvements for the Western North Atlantic, Caribbean and Gulf of Mexico ADCIRC Tidal Database (EC2015)." J. of Marine Science and Engineering 4(72). DOI:

10.3390/jmse4040072

Szpilka, C., K. Dresback, R. Kolar, and T. C. Massey. 2018. "Improvements for the Eastern North Pacific ADCIRC Tidal Database (ENPAC15).” J. of Marine Science and Engineering 6(131). doi:10.3390/jmse6040131

Torres, M. J., and N. C. Nadal-Caraballo. 2020. Rapid Tidal Reconstruction for the Coastal Hazards System and StormSim Part I: Coastal Texas and Louisiana. ERDC/CHL CHETN-I-99. Vicksburg, MS: US Army Engineer Research and Development Center.

Torres, M. J., N. C. Nadal-Caraballo, and A. A. Taflanidis. 2021. Rapid Tidal Reconstruction for the Coastal Hazards System and StormSim Part II: Puerto Rico and the US Virgin Islands. ERDC/CHL CHETN-I-101. Vicksburg, MS: US Army Engineer Research and Development Center, in review.

Torres, M. J., N. C. Nadal-Caraballo, E. Ramos-Santiago, M. O. Campbell, V. M. Gonzalez, J. A. Melby, and A. A. Taflanidis. 2020. "StormSim-CHRPS: Coastal Hazards Rapid Prediction System." Global Coastal Issues of 2020. Journal of Coastal Research Special Issue No. 95: 1320-1325.

Westerink, J. J., R. A. Luettich Jr., and N. Scheffner. 1993. ADCIRC: An Advanced ThreeDimensional Circulation Model for Shelves, Coasts, and Estuaries. Technical Report DRP-92-6. Vicksburg, MS: US Army Corps of Engineers, Waterways Experiment Station, Dredging Research Program. 


\section{Appendix: MATLAB Code}

The supporting MATLAB code disclosed in this section combines the methodology in a piecewise fashion, prompting for user input where appropriate.

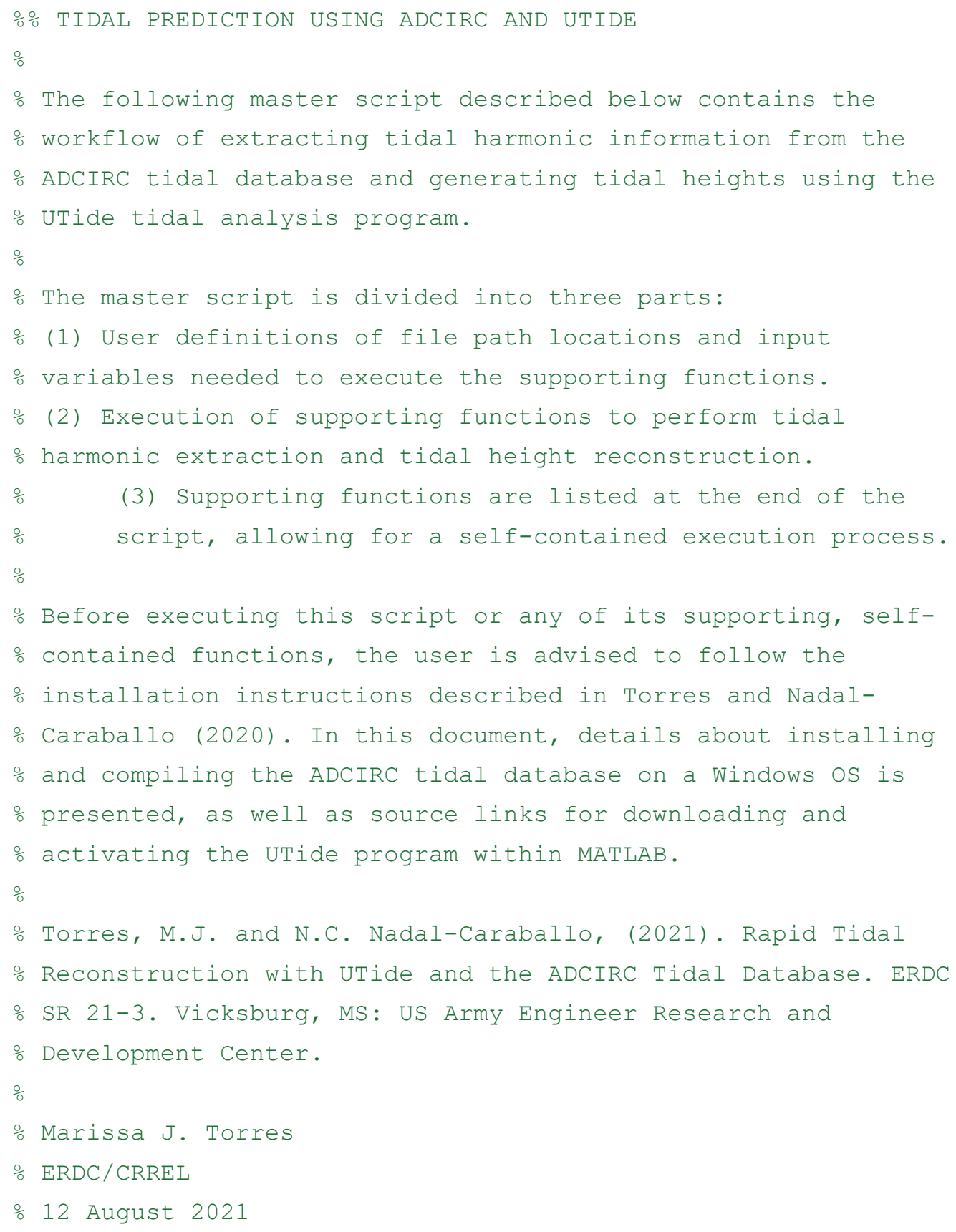




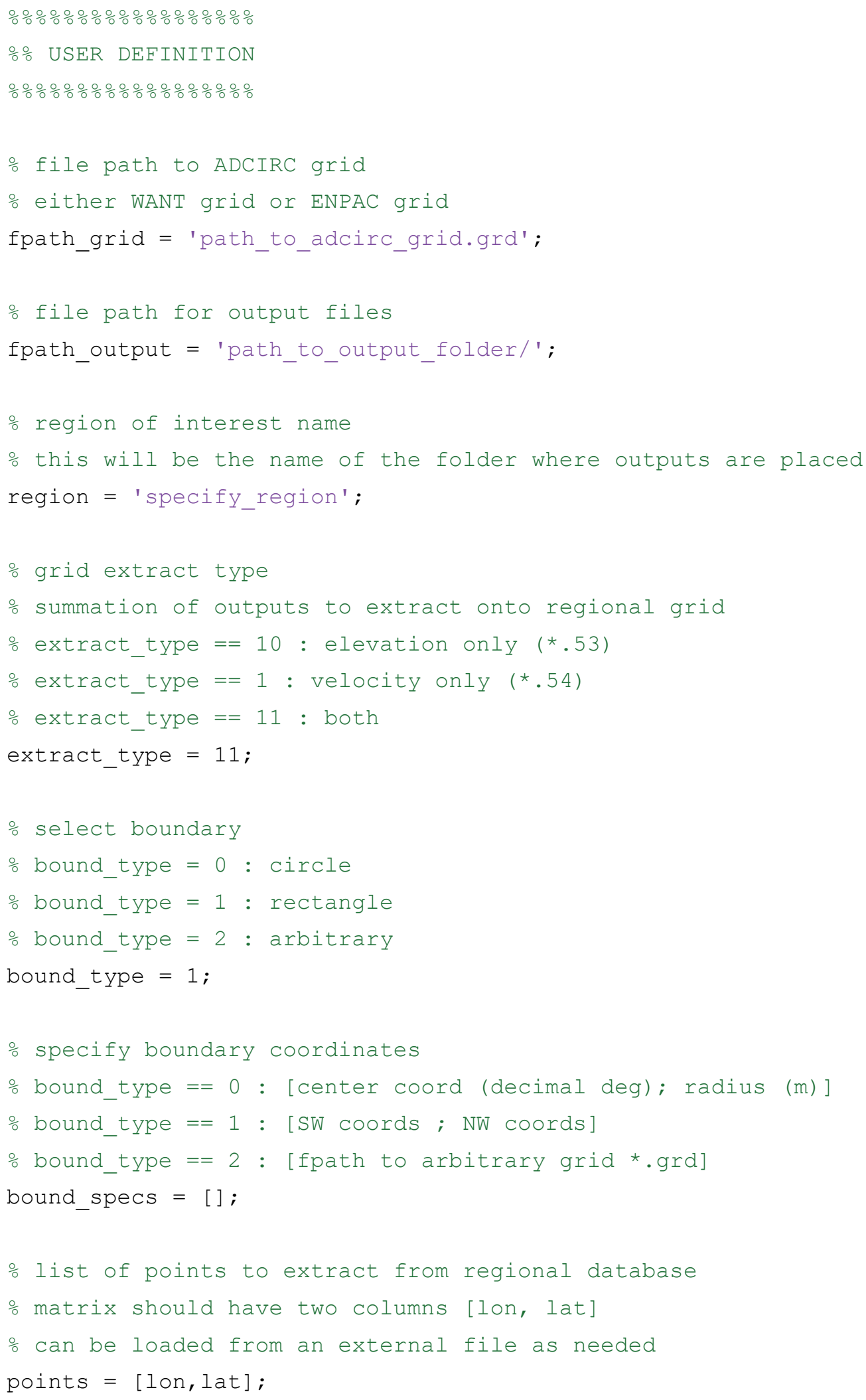




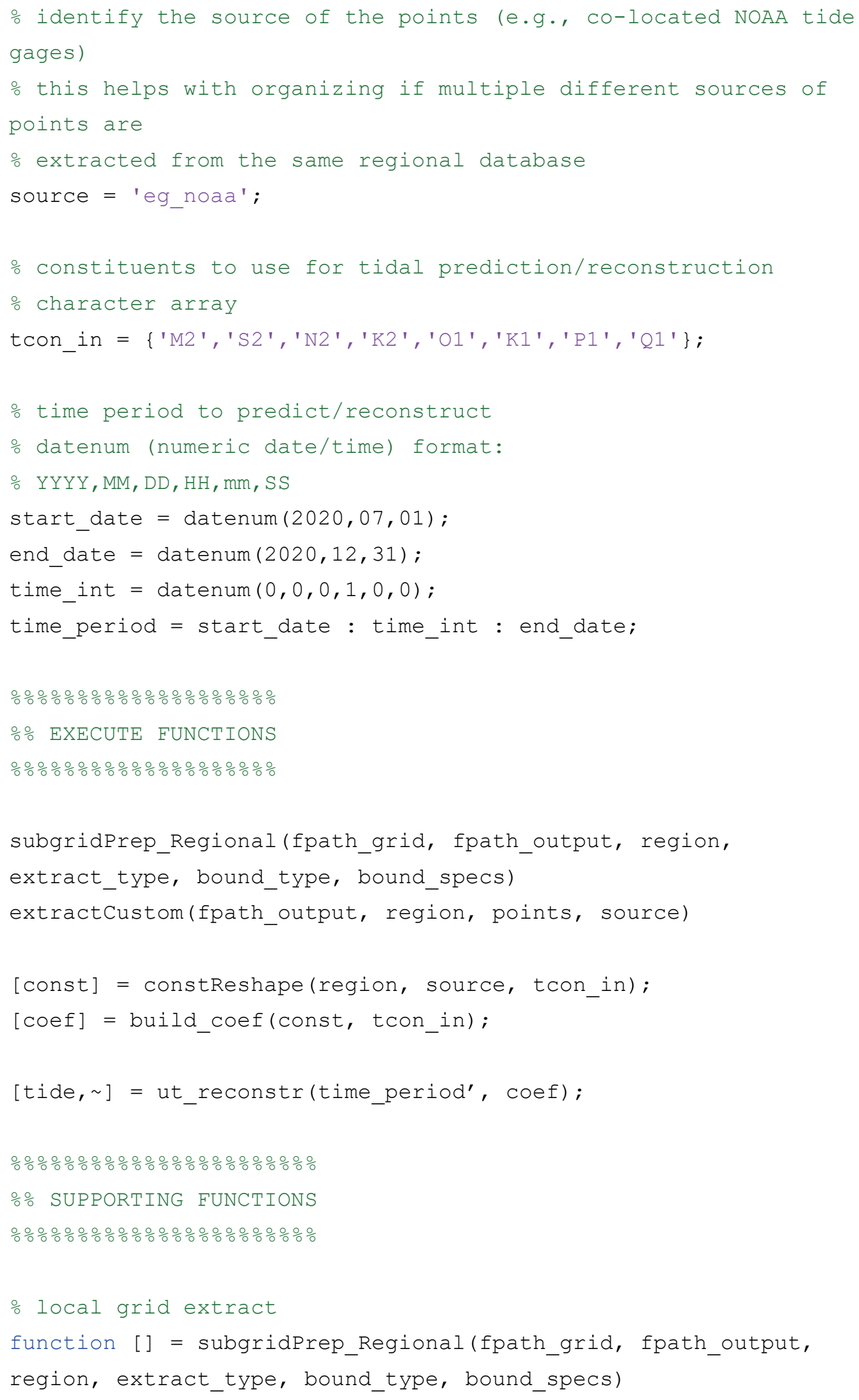




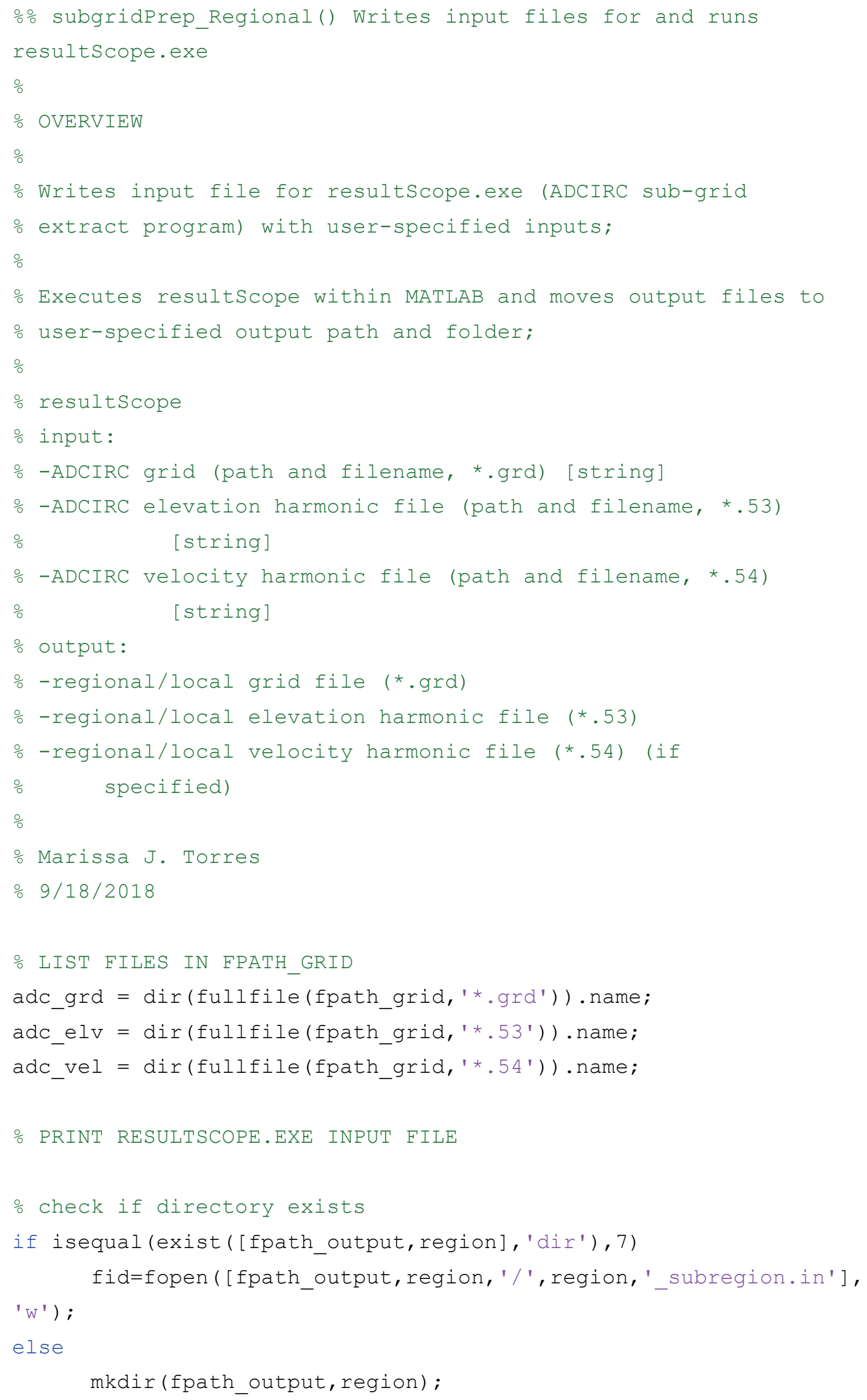




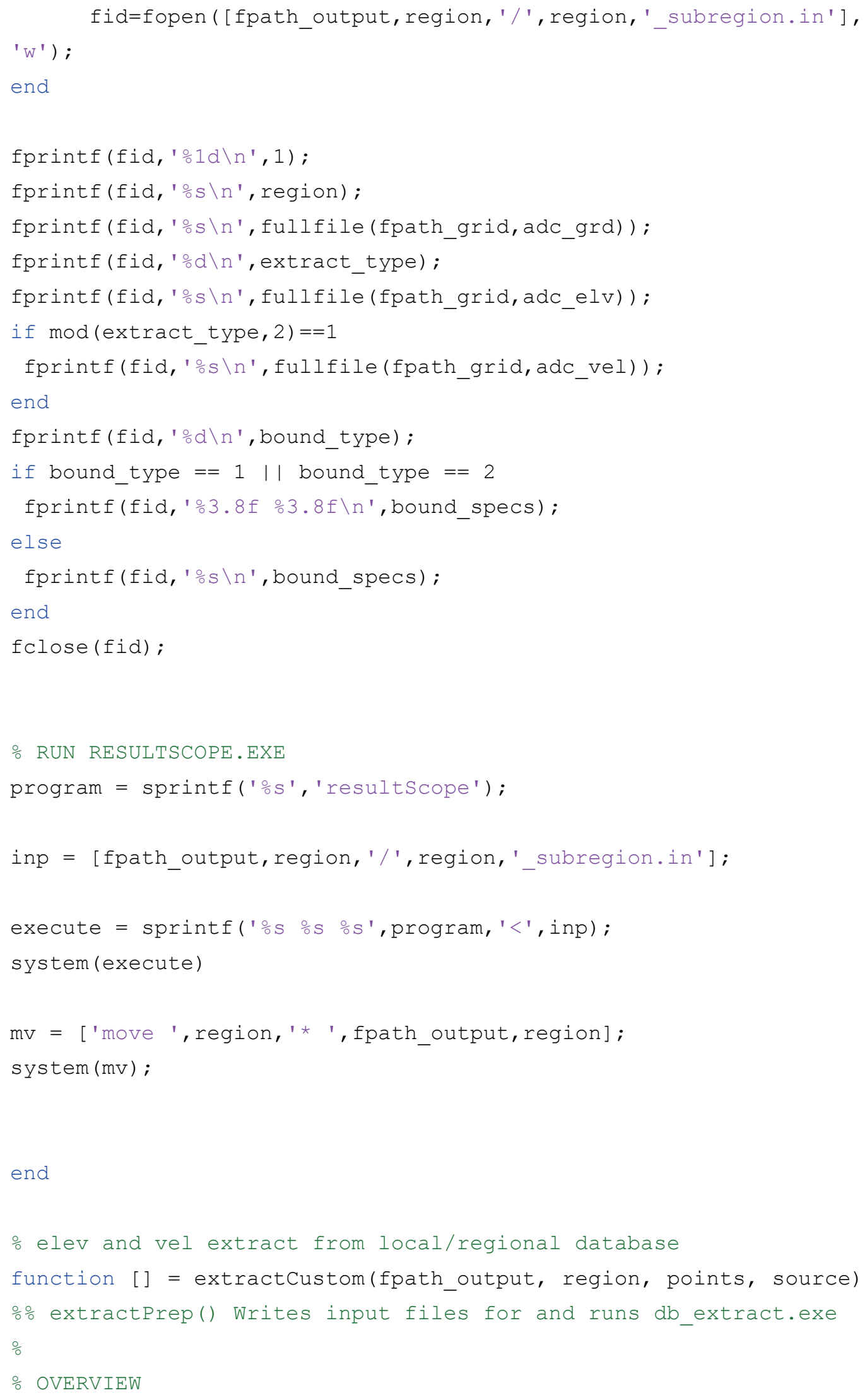




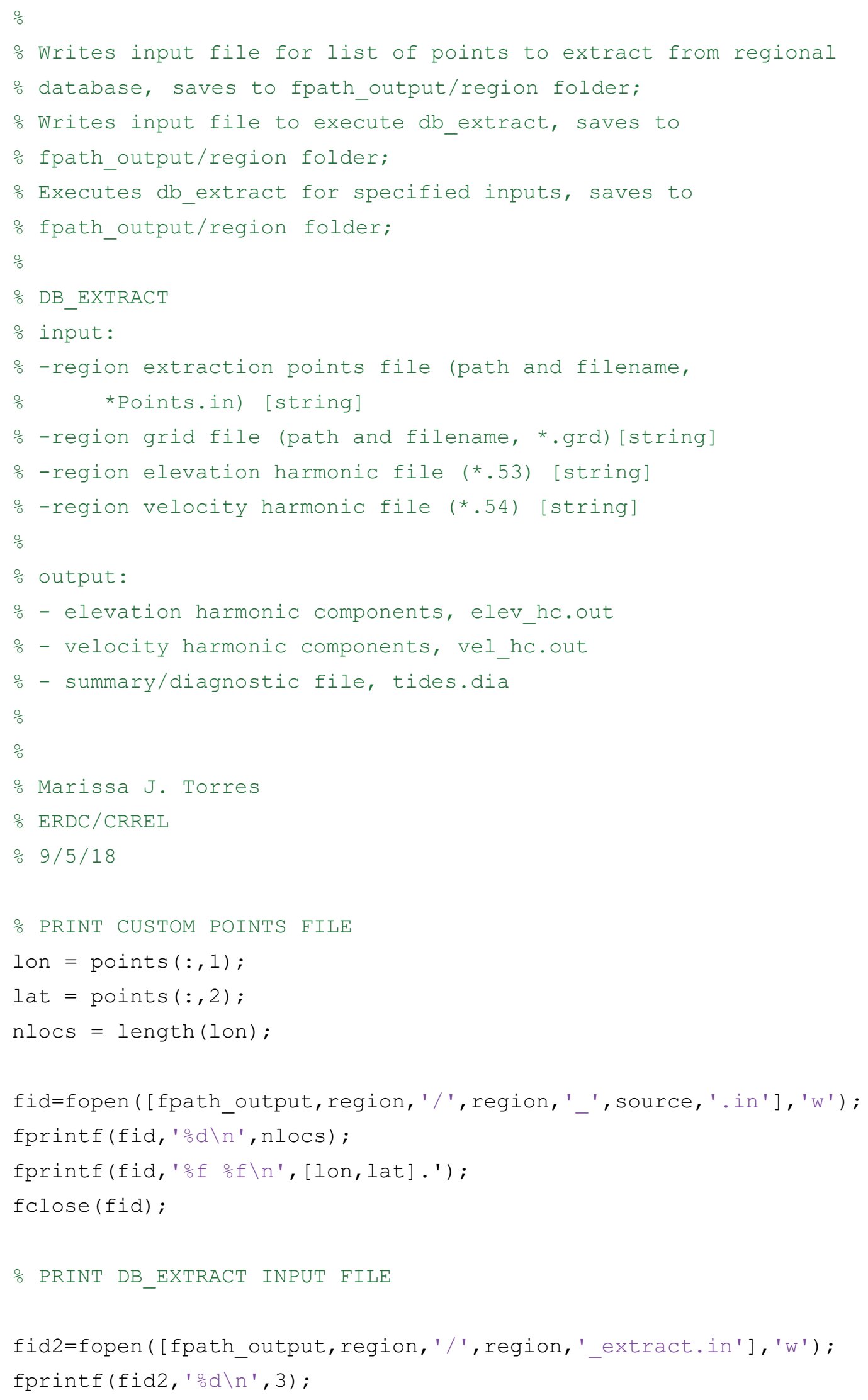




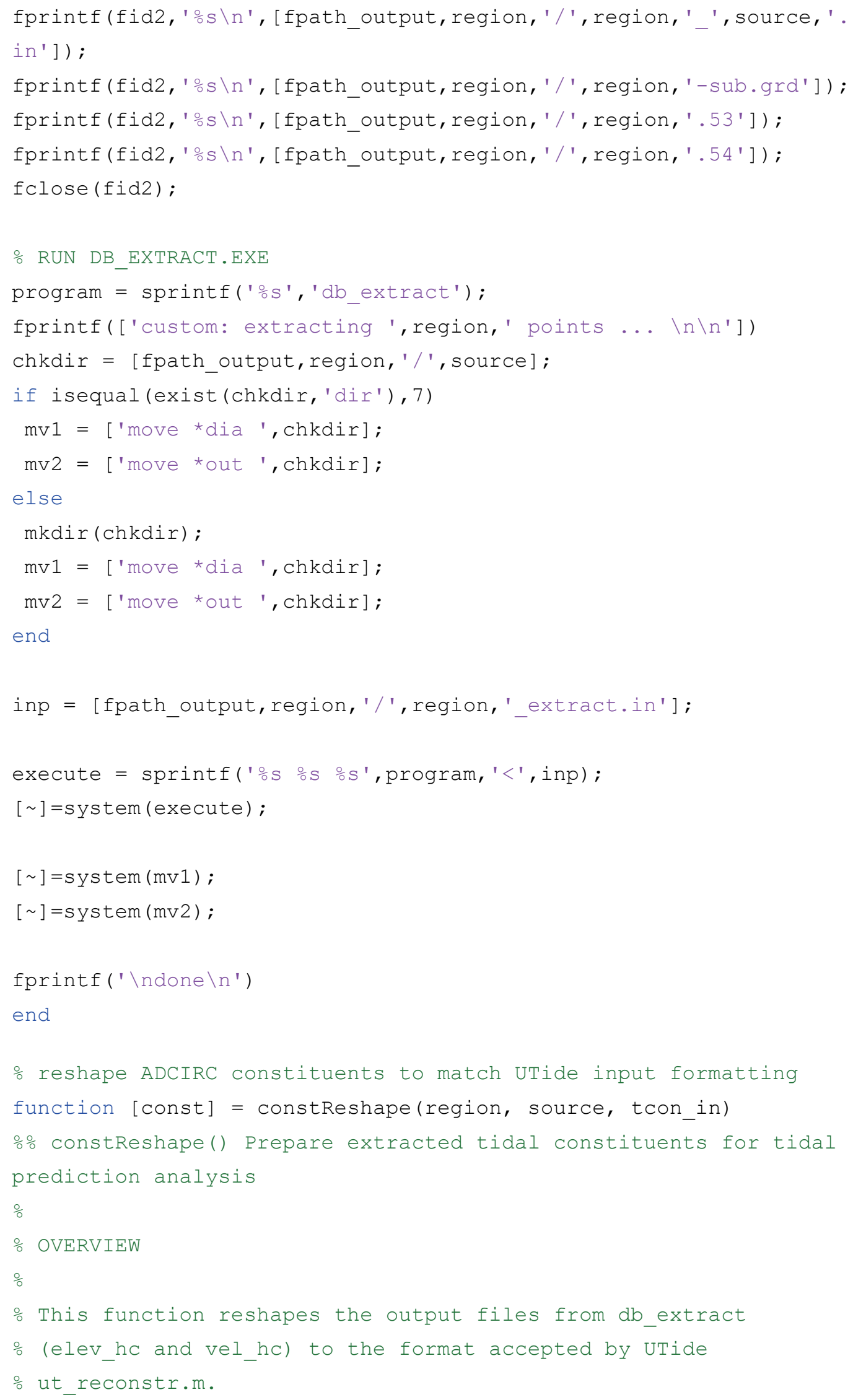




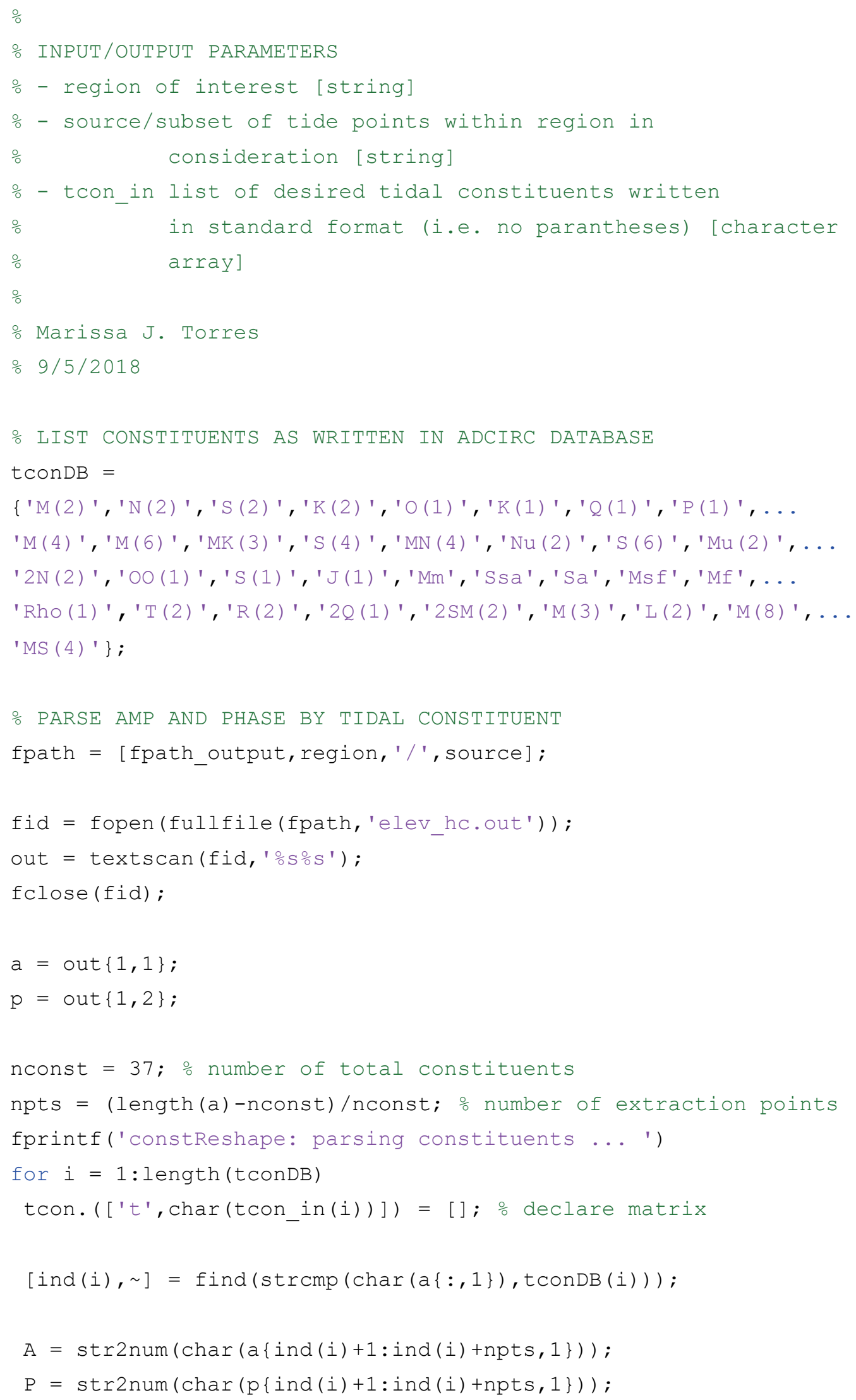




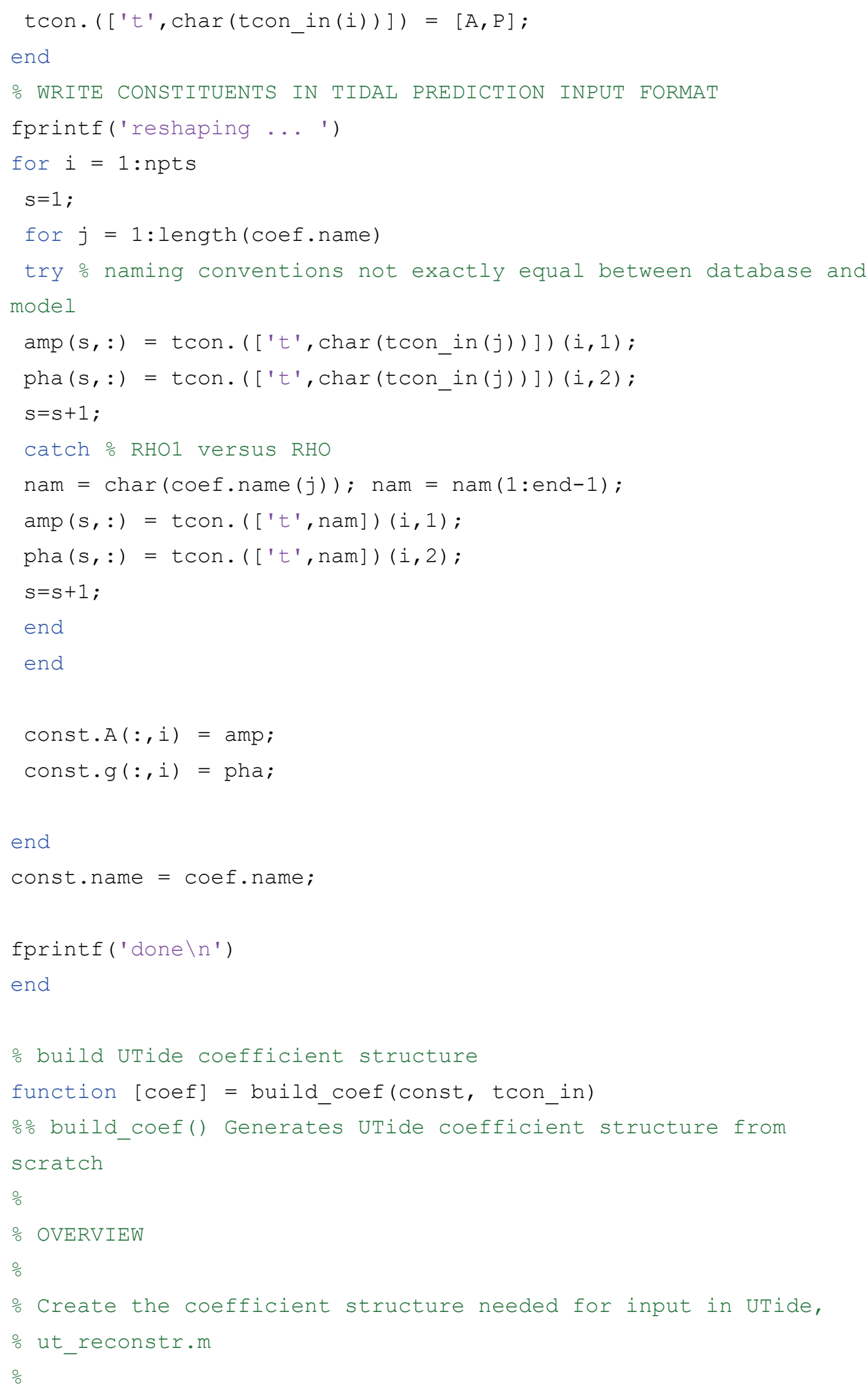




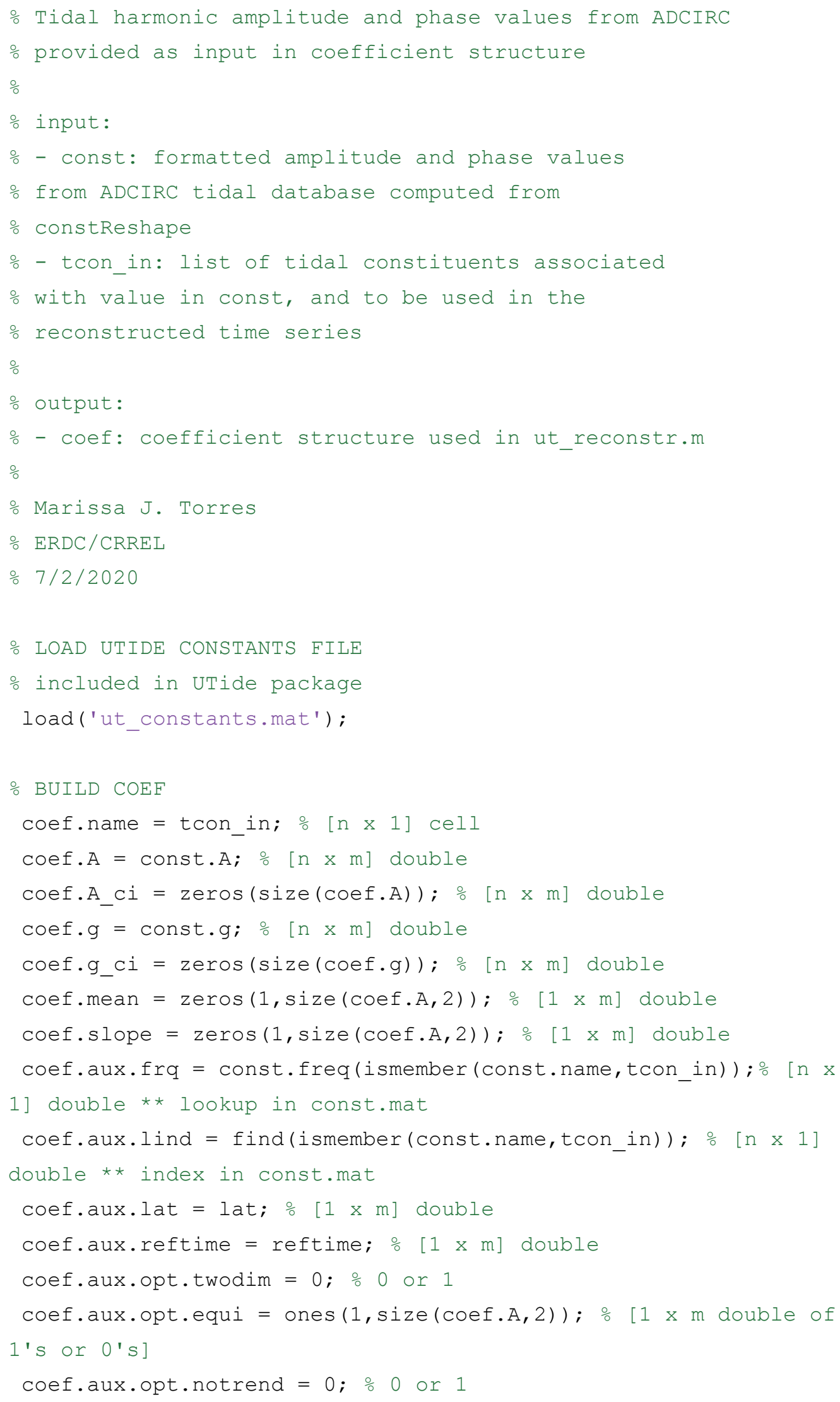




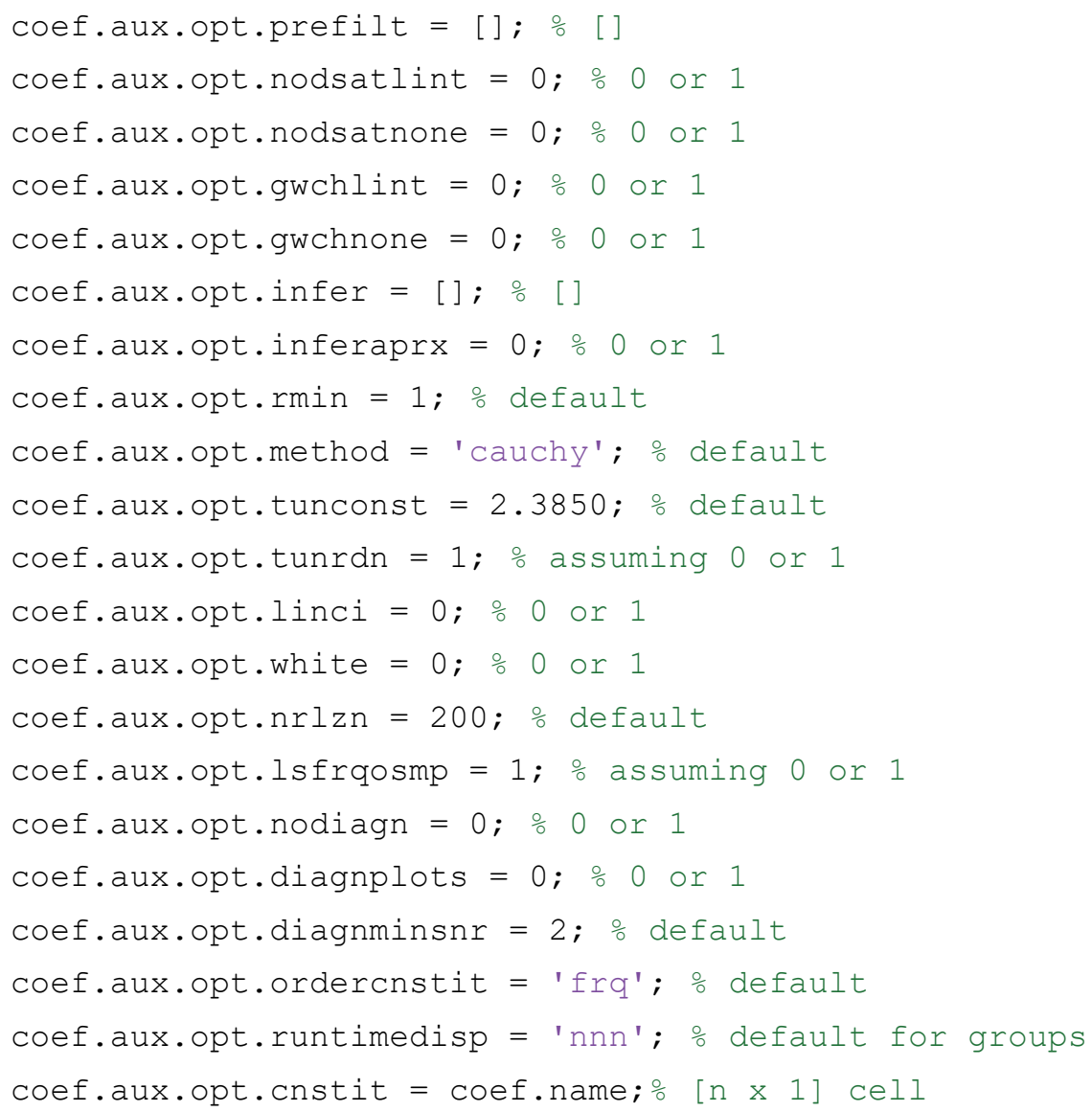

end 


\section{Unit Conversion Factors}

Most measurements and calculations for this study were presented in SI units. The following table can be used to convert SI units to English customary units.

\begin{tabular}{|l|l|l|}
\hline Multiply & By & To Obtain \\
\hline $\mathrm{m}$ & 3.28084 & $\mathrm{ft}$ \\
\hline $\mathrm{km}$ & 0.621371 & $\mathrm{mi}$ \\
\hline $\mathrm{km}$ & 0.539957 & $\mathrm{nmi}$ \\
\hline
\end{tabular}




\section{Acronyms and Abbreviations}

$\begin{array}{ll}\text { ADCIRC } & \text { Advanced Circulation } \\ \text { CHRPS } & \text { Coastal Hazards Rapid Prediction System } \\ \text { CHS } & \text { Coastal Hazards System } \\ \text { CO-OPS } & \text { Operational Oceanographic Products and Services } \\ \text { ENPAC } & \text { Eastern Pacific } \\ \text { IDE } & \text { Integrated Development Environment } \\ \text { IHO } & \text { International Hydrographic Organization } \\ \text { lon/lat } & \text { longitude/latitude } \\ \text { MSL } & \text { Mean sea level } \\ \text { NACCS } & \text { North Atlantic Coast Comprehensive Study } \\ \text { NOAA } & \text { National Oceanic and Atmospheric Administration } \\ \text { NOS } & \text { National Ocean Service } \\ \text { OS } & \text { Operating System } \\ \text { PCHA } & \text { Probabilistic Coastal Hazard Analysis } \\ \text { SACS } & \text { South Atlantic Coastal Study } \\ \text { StormSim } & \text { Stochastic Storm Simulation System } \\ \text { SWL } & \text { still water level } \\ \text { TC } & \text { tropical cyclone } \\ \text { USACE } & \text { US Army Corps of Engineers } \\ \text { UTide } & \text { Unified Tide } \\ \text { WNAT } & \text { Western North Atlantic } \\ \text { XC } & \text { extratropical cyclone }\end{array}$




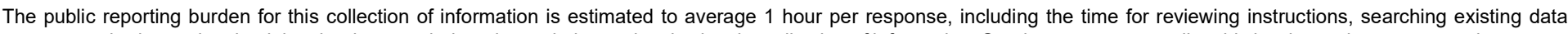

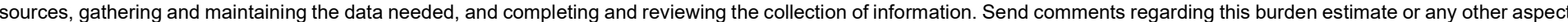

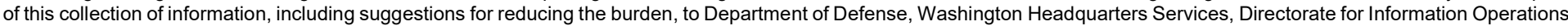

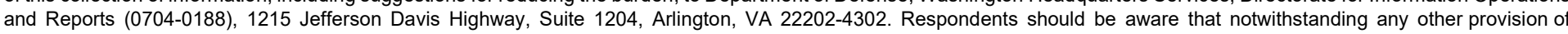
law, no person shall be subject to any penalty for failing to comply with a collection of information if it does not display a currently valid OMB control number.

PLEASE DO NOT RETURN YOUR FORM TO THE ABOVE ADDRESS.

\begin{tabular}{l|l|l}
\hline $\begin{array}{l}\text { 1. REPORT DATE } \\
\text { August 2021. }\end{array}$ & $\begin{array}{l}\text { 2. REPORT TYPE } \\
\text { Final Report }\end{array}$ & 3. DATES COVERED (From - To)
\end{tabular}

\section{TITLE AND SUBTITLE}

5a. CONTRACT NUMBER

Rapid Tidal Reconstruction with UTide and the ADCIRC Tidal Database

5b. GRANT NUMBER

5c. PROGRAM ELEMENT NUMBER

6. AUTHOR(S)

Marissa J. Torres and Norberto C. Nadal-Caraballo

\section{5d. PROJECT NUMBER}

5e. TASK NUMBER

5f. WORK UNIT NUMBER

\section{PERFORMING ORGANIZATION NAME(S) AND} ADDRESS(ES)

Cold Regions Research and Engineering Laboratory US Army Engineer Research and Development

Center

72 Lyme Road

Hanover, NH 03755-1290

9. SPONSORING/MONITORING AGENCY NAME(S) AND ADDRESS(ES)

US Army Engineer Research and Development Center

Vicksburg, MS 39180
Coastal and Hydraulics Laboratory

US Army Engineer Research and

Development Center

3909 Halls Ferry Road

Vicksburg, MS 39180-6199
8. PERFORMING ORGANIZATION REPORT NUMBER

ERDC SR-21-3
10. SPONSOR/MONITOR'S ACRONYM(S) ERDC

11. SPONSOR/MONITOR'S REPORT NUMBER(S)

\section{DISTRIBUTION/AVAILABILITY STATEMENT}

Approved for public release; distribution is unlimited.

13. SUPPLEMENTARY NOTES

Funding Account Code U4368973; AMSCO Code 031398

\section{ABSTRACT}

The quantification of storm surge is vital for flood hazard assessment in communities affected by coastal storms. The astronomical tide is an integral component of the total still water level needed for accurate storm surge estimates. Coastal hazard analysis methods, such as the Coastal Hazards System and the StormSim Coastal Hazards Rapid Prediction System, require thousands of hydrodynamic and wave simulations that are computationally expensive. In some regions, the inclusion of astronomical tides is neglected in the hydrodynamics and tides are instead incorporated within the probabilistic framework. There is a need for a rapid, reliable, and accurate tide prediction methodology to provide spatially dense reconstructed or predicted tidal time series for historical, synthetic, and forecasted hurricane scenarios. A methodology is proposed to combine the tidal harmonic information from the spatially dense Advanced Circulation hydrodynamic model tidal database with a rapid tidal reconstruction and prediction program. In this study, the Unified Tidal Analysis program was paired with results from the tidal database. This methodology will produce reconstructed (i.e., historical) and predicted tida heights for coastal locations along the United States eastern seaboard and beyond and will contribute to the determination of accurate still water levels in coastal hazard analysis methods.

\section{SUBJECT TERMS}

Flood control, Floods, Hurricanes, Hydrodynamics, Ocean circulation-Mathematical, Storm surges, Tides

\section{SECURITY CLASSIFICATION OF:}

\begin{tabular}{|l|c|l|}
\hline a. REPORT & b. ABSTRACT & c. THIS PAGE \\
Unclassified & Unclassified & Unclassified \\
\hline
\end{tabular}

17. LIMITATION OF ABSTRACT

SAR
18. NUMBER OF PAGES

53 19a. NAME OF RESPONSIBLE PERSON Marissa J. Torres

19b. TELEPHONE NUMBER (Include area code) 603-646-4283 